\title{
THE INFLUENCE OF CATIONS AND METHYLAMINE ON STRUCTURE AND FUNCTION OF THYLAKOID MEMBRANES FROM BARLEY CHLOROPLASTS
}

\author{
by \\ ROBERT M. SMILLIE 1 KNUD W. HENNINGSEN ${ }^{2}$ \\ NIELS C. NIELSEN ${ }^{3}$, DITER von WETTSTEIN \\ Institute of Genetics, University of Copenhagen \\ $\emptyset$ ster Farimagsgade 2A, DK-1353 Copenhagen K, Denmark \\ and \\ Department of Physiology - Carlsberg Laboratory \\ Gamle Carlsberg Vej 10 - DK-2500 Copenhagen Valby
}

1. Visiting Professor, Lniversity of Copenhagen, 1973-74. Present address: Plant Physiology Unit, CSIRO Division of Food Research, P. O. Box 52, North Ryde 2113, Sydney, Australia.

2. Present address: Department of Genetics, The Royal Veterinary and Agricultural University, DK-1870 Copenhagen, Denmark.

3. Present address: Department of Biochemistry and Biophysics, University of California, Davis, Calif. 95616.

Key Words: Chloroplast membranes, methylamine, Hill activity, proton pump activity, thylakoid stacking.

\footnotetext{
The effects of cations on the structure and activity of isolated barley (Hordeum vulgare cv. Svalöfs Bonus) chloroplast lamellar systems were studied. Three separate effects of cations were recognizable. (1) Cations in high concentrations (in excess of $100-200 \mathrm{~m} \mathrm{M} \mathrm{NaCl}$ ) are required to maintain granal stacks once the outer chloroplast envelope is broken. In $30 \mathrm{mM} \mathrm{NaCl}$ the majority of the lamellar systems exist as well-separated thylakoids, even in the presence of high concentrations of sucrose $(330$ and $660 \mathrm{mM})$. The lamellar systems photoreduce ferricyanide at coupled rates whether they are in the granal or non-granal configuration. (2) Cations are required for Hill reaction activity. This requirement becomes apparent following loss of thylakoid membrane integrity at very low cation concentrations. Maximum activation of the photoreduction of ferricyanide occurs at $30 \mathrm{mM} \mathrm{NaCl}$, and divalent ions $\left(\mathrm{Mg}^{++}, \mathrm{Ca}^{++}, \mathrm{Mn}^{++}\right)$are 12 times more effective than monovalent ions $\left(\mathrm{Na}^{+}\right.$, $\mathrm{K}^{+}$). (3) Cations are necessary to preserve the integrity of thylakoid membranes. Below about $8 \mathrm{mM} \mathrm{NaCl}$, the thylakoids swell and this change is accompanied by progressive loss of Hill activity and the capacity to maintain a light-dependent proton gradient. Divalent cations are more than 200 times as effective as monovalent ions in preventing these changes. Hill reaction activity, but not proton pump activity, is regained by adding cations back to the swollen thylakoids (cation effect 2, above) and the new rate of Hill reaction activity is the same as in chloroplasts uncoupled with methylamine. The re-establishment of Hill reaction activity is accompanied by appression of the swollen thylakoids. The uncoupler methylamine causes stacking of thylakoids and collapsing of intrathylakoidal spaces.
} 


\section{INTRODUCTION}

Spinach chloroplasts undergo profound changes in structure when suspended in a medium containing a low concentration of salt $(20,21)$. A most striking structural alteration observed first by IZAWA and GooD was the virtual disapperance of grana in chloroplasts isolated in a high salt medium and then exposed to a lower concentration of salt (21). Electron microscopy after this procedure revealed that the naked lamellar systems of the chloroplasts consisted almost entirely of widely separated thylakoids. Other properties indicative of changes in membrane organization were measured. The volume of the chloroplast lamellar systems was increased and their light scattering properties decreased $(20,21)$. However, photosynthetic electron transport activity was largely unaffected by these structural changes and IZAWA and GOOD concluded that the appression of thylakoids in granal stacks is not important for the Hill reaction. Yet in the decade following these observations there have been many attempts to correlate changes in photosynthetic electron transport activity, especially of reactions involving photosystem II, with changes in grana structure. For instance, comparisons have been made between the activities of higher plant chloroplasts containing grana with those of chloroplasts deficient in or containing reduced amounts of granal lamellae such as occurs in the early stages of chloroplast development (8, 40 ), in mature chloroplasts in certain $\mathrm{C}_{4}$ plants $(2,44)$, and in cases where chloroplast development has been arrested either by environmental factors, e. g. either the duration or intensity of light $(1,43)$ and mineral deficiencies $(5,17,45)$, or by gene mutation $(6,18,43)$. In a number of these and related comparative studies, differences in photosynthetic electron transport activities were correlated with or even attributed to variations in the extent of grana development. It is obvious that the interpretation of results of such comparisons as well as those of many other studies of chloroplast structure and function would be influenced by any major structural reorganization taking place during isolation or assay of the chloroplasts. The "low salt" concentrations employed by IZAWA and GoOD were not in fact all that low, and grana-free chloroplasts were found after fixation in a medium which included $50 \mathrm{mM}$ tricine- $\mathrm{NaOH} \mathrm{pH} 7.3$ (of which 20 per cent would be in the anionic form as sodium tricinate) and $10 \mathrm{mM} \mathrm{K}^{+}$from potassium ferricyanide also present in the medium (21). This raises the possibility that losses in grana structure may happen in many of the media commonly employed for the preparation or assay of isolated chloroplasts.

At salt concentrations lower than those used by IZAWA and GOOD, changes become evident in photosynthetic electron transport reactions of isolated chloroplast membranes. Non-cyclic and cyclic photophosphorylation activities are lost in spinach chloroplasts washed in dilute EDTA or suspended in distilled water $(23,41$, 46 ), but this loss of activity is prevented if a 100 $\mu \mathrm{M}$ concentration of divalent cation is present throughout the treatments. The decrease in phosphorylation parallels an increase in the rate of photoreduction of ferricyanide and 2,3', 6-trichlorophenol indophenol $(23,46)$ that is consistent with a gradual uncoupling of the chloroplasts as the solute concentration is lowered. However, the role of cations in photoreductive reactions is not clear. While removal of cations can cause an increase in ferricyanide photoreduction, SHAvit and AVRON (41) have shown that under some conditions the addition of cations stimulated ferricyanide photoreduction, while Gross et al. (16) on the other hand reported inhibition of this activity by cations. Many other phenomena in isolated chloroplasts are affected by cations. These include besides changes in structure $(7,15,16,21,31,39,46)$, chloroplast lamellar volume $(13,14,20,38,41$, $51)$ and light scattering properties $(7,15,16,20$, $26,27,31,34,41,50)$ changes in chlorophyll absorption (15), fluorescence $(9,11,12,15,16$, $19,24,26,27,30-35,50)$ and delayed light emission $(4,16,29,36)$. The 515-nm absorption change $(13,16)$, the fluorescence of probes

Abbreviations: BSA - bovine serum albumin, DCMU - 3 (3,4-dichlorophenyl)-1,1-dimethyl urea, DBMIB - 3methyl-6-isopropyl-p-benzoquinone 
partitioned into chloroplast membrane lipids $(16,31,50)$ and the size and distribution of large particles exposed by freeze etching on granal membrane surfaces (51) are also influenced by the cation concentration. Cations at relatively high concentrations promote reduction of the electron carrier pool between photosystems I and II (28) and are necessary to demonstrate Emerson dual-wave length enhancement in isolated chloroplasts $(28,42,48)$. Partly because of the multiplicity of these effects of salt and the diverse range of concentrations involved, a clear picture of the action of salts on chloroplast membrane structure and function has not emerged. It is apparent though that for most of these changes the salt is not acting solely osmotically and the changes are due to the cations rather than the anions. Further, divalent cations are much more effective than monovalent cations.

These considerations indicate that it is of paramount importance in studies with isolated chloroplasts to understand the nature of the effects of cations on chloroplast membrane structure and activity and to be aware of the time course of these effects and the critical concentration ranges involved. With this in view we have examined the action of salts on the structure and electron transport activity of isolated chloroplast lamellar systems. The chloroplasts were isolated from leaves of barley, a $\mathrm{C}_{3}$ plant containing chloroplasts with numerous well-developed grana.

\section{MATERIAL AND METHODS}

\subsection{Plant Material.}

Barley seedlings (Hordeum vulgare cv. Svalöfs Bonus) were grown at $21^{\circ} \mathrm{C}$ in plastic trays containing vermiculite moistened with tap water, and under constant illumination of 3200 lux of fluorescent light.

\subsection{Preparation of Chloroplasts}

Apical $5-\mathrm{cm}$ segments $(10 \mathrm{~g})$ of the primary leaves were cut into smaller segments of approximately $2 \mathrm{~mm}$ and suspended in $50 \mathrm{ml}$ of $30 \mathrm{mM} \mathrm{NaCl}, 50 \mathrm{mM}$ Tricine- $\mathrm{NaOH}$ pH 7.5, 1 $\mathrm{mM}$ EDTA, and $0.5 \%(\mathrm{w} / \mathrm{v})$ bovine serum albumin (BSA). In all other media (including assay media) EDTA was omitted, and the concentration of $\mathrm{NaCl}$ was $30 \mathrm{mM}$, Tricine $5 \mathrm{mM}$, and BSA $0.05 \%(w / v)$. In some of the experiments the salt concentration was varied, and in others sucrose was included in the grinding, wash and assay media. These variations are detailed in the text. The chloroplasts were released by blending the leaf segments in an Omni Mixer at full line voltage for two periods of $10 \mathrm{sec}$ each. After the blending, the brei was pressed through two layers of $28 \mu \mathrm{m}$ nylon mesh and then filtered through two layers of Miracloth (Calbiochem., La Jolla, Calif.). The chloroplasts were sedimented by centrifugation at $1000 \mathrm{~g}$ for $5 \mathrm{~min}$ and washed by resuspending in $30 \mathrm{mM} \mathrm{NaCl}, 5$ $\mathrm{mM}$ Tricine- $\mathrm{NaOH} \mathrm{pH} 7.5$ and $0.05 \%(\mathrm{w} / \mathrm{v})$ BSA and centrifuging as before. The chloroplasts were finally suspended in the same medium. Chlorophyll was estimated spectrophotometrically after extraction in alkaline $80 \%$ $(w / v)$ acetone (10).

\subsection{Photoreduction of Ferricyanide}

The rate of photoreduction of ferricyanide, was measured by the decrease in absorbance at 420 $\mathrm{nm}$ using a Cary 17 recording spectrophotometer. The temperature was $23^{\circ} \mathrm{C}$ and the sample was illuminated with red light at $6.8 \times 10^{5}$ ergs $\mathrm{cm}^{-2} \mathrm{sec}^{-1}$.

\subsection{Proton Pump Measurement}

The light-dependent generation of a proton gradient was measured as described previously (43). The sample was illuminated with red light $\left(4.6 \times 10^{5} \mathrm{ergs} \mathrm{cm}^{-2} \mathrm{sec}^{-1}\right)$ and the resulting $\mathrm{pH}$ change measured using a Radiometer combination electrode (GK 2322C).

\subsection{Electron Microscopy}

Plastid suspensions were fixed by adding a purified concentrated glutaraldehyde solution in water to give a final concentration of $3 \%$ (w/v) glutaraldehyde. During the first $15 \mathrm{~min}$ of fixation the suspensions were kept under the same light and temperature conditions used prior to addition of the glutaraldehyde. Fixa- 
Table I

Morphology of barley cholorplast lamellar systems isolated in different media.

Chloroplast lamellae were isolated as described in Materials and Methods. Any variations in the salt and buffer concentrations for the isolation, wash and suspension media are listed in the table under "Medium«. In some experiments sucrose was included in all media and this is noted also in the table. The choloroplast lamellae were illuminated for the times indicated in the table before fixation and thereafter during the fixation period at a distance of $30 \mathrm{~cm}$ from a $60 \mathrm{~W}$ Tungsten lamp, except where indicated by an asterisk. In this case the illumination was the same as for the photochemical measurements, i.e. red light of $6.8 \times 10^{5} \mathrm{ergs} \mathrm{cm}^{-2} \mathrm{sec}^{-1}$. Electron micrographs of the different categories of lamellar systems are given in Fig. 1 to 13. i.th.sp. $=$ intrathylakoid space.

\begin{tabular}{|c|c|c|c|c|c|c|c|c|c|}
\hline \multicolumn{3}{|c|}{ Treatment } & \multirow{3}{*}{$\begin{array}{l}\text { Resus- } \\
\text { pended } \\
\text { in }\end{array}$} & \multirow{3}{*}{$\begin{array}{c}\text { Number } \\
\text { of } \\
\text { Lamellar } \\
\text { Systems } \\
\text { Analysed }\end{array}$} & \multicolumn{5}{|c|}{ Lamellar Systems Category, \% } \\
\hline \multirow[t]{2}{*}{ Medium } & \multirow{2}{*}{$\begin{array}{c}\text { Light } \\
\text { min }\end{array}$} & \multirow{2}{*}{$\begin{array}{l}\text { Temp. } \\
{ }^{\circ} \mathrm{C}\end{array}$} & & & \multicolumn{2}{|c|}{ With Grana } & \multicolumn{2}{|c|}{ Without Grana } & \multirow{2}{*}{$\begin{array}{l}\text { Chloro- } \\
\text { plasts } \\
\text { with } \\
\text { Enve- } \\
\text { lope }\end{array}$} \\
\hline & & & & & $\begin{array}{c}1 \\
\text { i.th.sp. } \\
\text { narrow }\end{array}$ & $\begin{array}{c}2 \\
\text { i.th.sp. } \\
\text { wide }\end{array}$ & $\begin{array}{c}3 \\
\text { i.th.sp. } \\
\text { wide }\end{array}$ & $\begin{array}{c}4 \\
\text { i.th.sp. } \\
\text { dilated }\end{array}$ & \\
\hline $\begin{array}{l}30 \mathrm{mM} \mathrm{NaCl} \\
30 \mathrm{mM} \mathrm{NaCl} \\
30 \mathrm{mM} \mathrm{NaCl}\end{array}$ & $\begin{array}{l}0 \\
0 \\
3^{*}\end{array}$ & $\begin{array}{r}0 \\
23 \\
23\end{array}$ & & $\begin{array}{l}103 \\
122 \\
118\end{array}$ & & $\begin{array}{l}27.2 \\
31.1 \\
37.3\end{array}$ & $\begin{array}{l}1.9 \\
9.8 \\
7.6\end{array}$ & $\begin{array}{l}70.9 \\
59.1 \\
55.1\end{array}$ & \\
\hline $\begin{array}{l}30 \mathrm{mM} \mathrm{NaCl} \\
30 \mathrm{mM} \mathrm{NaCl} 5 \mathrm{mM} \\
\mathrm{PO}_{4}(-\mathrm{Tricine}) \\
30 \mathrm{mM} \mathrm{NaCl}, 5 \mathrm{mM} \\
\mathrm{PO}_{4} \\
30 \mathrm{mM} \mathrm{NaCl} \\
50 \mathrm{mM} \mathrm{PO}_{4}(-\mathrm{NaCl})\end{array}$ & $\begin{array}{l}2 \\
2 \\
2 \\
2 \\
0\end{array}$ & $\begin{array}{l}23 \\
23 \\
23 \\
23 \\
23\end{array}$ & $\begin{array}{c}30 \mathrm{mM} \mathrm{NaCl}_{1} \\
5 \mathrm{mM} \mathrm{PO} \\
30 \mathrm{mM} \mathrm{NaCl}_{4}\end{array}$ & $\begin{array}{l}79 \\
70\end{array}$ & & $\begin{array}{l}32.9 \\
21.4 \\
26.3 \\
\\
23.0 \\
23.7\end{array}$ & $\begin{array}{l}2.5 \\
5.7 \\
1.3 \\
3.2 \\
8.6\end{array}$ & $\begin{array}{l}64.6 \\
72.9 \\
72.4 \\
73.8 \\
67.7\end{array}$ & \\
\hline $\begin{array}{l}\text { 330mM sucrose, } \\
5 \mathrm{mM} \mathrm{PO}_{4} \\
(-\mathrm{Tricine}) \\
30 \mathrm{mM} \mathrm{NaCl}, 330 \mathrm{mM} \\
\text { sucrose } \\
30 \mathrm{mM} \mathrm{NaCl}, 660 \mathrm{mM} \\
\text { sucrose }\end{array}$ & $\begin{array}{l}2 \\
3^{*}\end{array}$ & $\begin{array}{l}23 \\
23\end{array}$ & & $\begin{array}{l}103 \\
106 \\
128\end{array}$ & & $\begin{array}{r}14.6 \\
5.7 \\
10.9\end{array}$ & $\begin{array}{l}26.2 \\
57.5 \\
49.3\end{array}$ & $\begin{array}{l}59.2 \\
36.8 \\
39.8\end{array}$ & $\begin{array}{c}12.5 \\
7\end{array}$ \\
\hline $\begin{array}{l}350 \mathrm{mM} \mathrm{NaCl} \\
350 \mathrm{mM} \mathrm{NaCl}, \\
\text { 100mM Tricine }\end{array}$ & $\begin{array}{l}3 * \\
2\end{array}$ & $\begin{array}{l}23 \\
23\end{array}$ & & $\begin{array}{r}91 \\
117\end{array}$ & $\begin{array}{l}100 \\
100\end{array}$ & & & & $\begin{array}{l}4.4 \\
2.6\end{array}$ \\
\hline
\end{tabular}

tion was then continued for $105 \mathrm{~min}$ at $0^{\circ} \mathrm{C}$ in light or darkness and after washing with $70 \mathrm{mM}$ phosphate buffer at $\mathrm{pH} 7.2$, the samples were postfixed for $1 \mathrm{hr}$ with osmium tetroxide in 70 $\mathrm{mM}$ phosphate buffer $\mathrm{pH}$ 7.2. After dehydration by a graded series of ethanol washes, the material was embedded in a low-viscosity epoxy-resin according to SPURR's formula (47). Sections were cut on a Reichert ultramicrotome and analysed in a Siemens Elmiskop IA or a Zeiss EM9A after contrasting with uranyl acetate and lead citrate.
Figure 1. Barley chloroplast lamellar systems of category I with tightly stacked grana and an intrathylakoid space about $15 \mathrm{m \mu}$ thick. Isolated in medium containing $350 \mathrm{mM} \mathrm{NaCl}$. For Fig. 1 to 24 the lamellar systems were isolated in media containing in addition to $\mathrm{NaCl}$ and where stated also sucrose, $50 \mathrm{mM}$ Tricine $\mathrm{pH} 7.5,1 \mathrm{mM}$ EDTA and $0.5 \%(\mathrm{w} / \mathrm{v})$ BSA, and washed and suspended in media containing $5 \mathrm{mM}$ Tricine $\mathrm{pH} 7.5$ and $0.05 \%(\mathrm{w} / \mathrm{v})$ BSA. The $\mathrm{NaCl}$ and sucrose were included in the isolation, wash and suspension media and the actual concentrations used are given in each figure legend. $\times 18,000$.

Figure 2. Higher magnification of lamellar system from preparation in Figure 1. $\times 64,000$. 

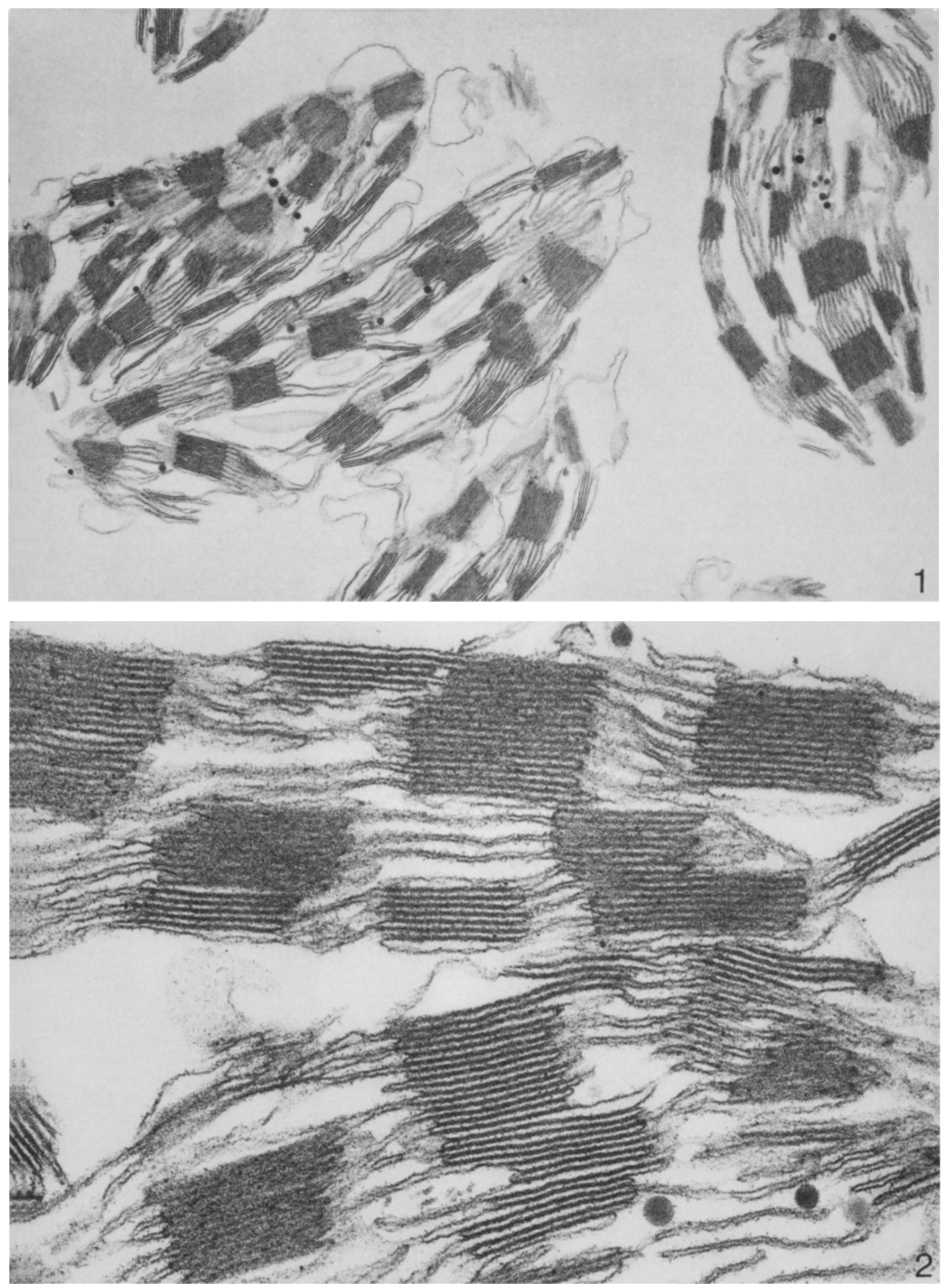


\section{RESULTS}

\subsection{Morphology and Activity of Chloroplast} Lamellar Systems Isolated with Different Media In agreement with earlier studies (3), the majority of chloroplasts isolated from green barley seedlings in media containing sucrose or salt consisted of naked lamellar systems. When the chloroplasts were prepared with $330 \mathrm{mM}$ sucrose or $350 \mathrm{mM} \mathrm{NaCl}$ between 3 and 12 per cent of the chloroplasts retained an envelope (Table I). The lamellar systems of these whole chloroplasts had, with regard to grana structure and thickness of intrathylakoid spaces, an organization corresponding to that observed after fixation of leaf pieces.

The naked lamellar systems can be classified into a number of different categories, using the presence or absence of grana and the width of the intrathylakoid space as criteria. Category 1 (Fig. 1 and 2) refers to naked lamellar systems with a morphology essentially identical to that in whole chloroplasts in situ. Their grana consisted of tightly stacked thylakoids having intrathylakoid spaces about $15 \mathrm{~m} \mu$ wide. As is evident from Table 1 , this category was only obtained by using a high concentration of salt (e. g. $350 \mathrm{mM} \mathrm{NaCl}$ ). All of the lamellar systems in a suspension had essentially the same morphology. It should be noted that this configuration of the membrane system was not retained by sucrose concentrations as high as $660 \mathrm{mM}$ (Fig. 8, 12 and Table I).

Isolation of chloroplasts in a medium containing $30 \mathrm{mM} \mathrm{NaCl}$ yielded a mixture of lamellar systems which could be separated into three categories on the basis of their morphology (Fig. 3). Category 2 contained grana with wide to dilated intrathylakoid spaces, whereas categories 3 and 4 were devoid of grana or nearly so. These two grana-deficient categories were distinguished from each other by the thickness of their intrathylakoid spaces, category 3 having a wide 15 to $30 \mathrm{~m} \mu$ space and category 4 a dilated 30 to $60 \mathrm{~m} \mu$ one.

Typical examples of category 2 of the lamellar systems are reproduced in Figures 4 and 5. Almost complete stacking of the grana thylakoids was found in some lamellar systems (Fig. 4 and 10) although it was more usual to find that the grana thylakoids had become partially separated (Fig. 5 and 11). The intrathylakoid spaces, especially in the intergrana regions, were of rather uneven width and varied in thickness between 20 and $60 \mathrm{~m} \mu$.

Complete unstacking of the grana thylakoids as in category 3 resulted in large and concentrically arranged thylakoids with rather uniform intradisc spaces (category 3; Fig. 6, 7, 8 and 12). Such grana-free lamellar systems have already been described by IZAWA and GOOD (21) who suspended spinach chloroplasts in $50 \mathrm{mM}$ Tricine-NaOH. The intradisc spaces in the barley preparations varied between 15 and 30 $\mathrm{m} \mu$, but were in most cases wider than in lamellar systems suspended in high salt (350 $\mathrm{mM} \mathrm{NaCl}$ ) media (category 1). In these lamellar systems of category 3 , it was no longer possible to identify the grana-specific membrane areas morphologically. The extended unpaired thylakoids were heid together at a few locations by small grana-like associations. Two to four thylakoids were stacked over a short area (Fig. 7,8 and 12) giving small "grana similar to those observed in etioplasts of dark-grown seedlings.

Category 4 (Fig. 9 and 13) also consisted of completely unstacked thylakoids, but with intrathylakoid spaces dilated to yield a membrane separation of between 30 and $60 \mathrm{~m} \mu$. Membrane areas capable of stacking were not distinguishable from intergrana areas.

The frequencies of the chloroplast lamellar categories 2, 3 and 4 have been determined for the various isolation media and conditions used in this study (Table I). All three categories were present in preparations made with media containing $30 \mathrm{mM} \mathrm{NaCl}$. Typically, 50 to 70 per cent of the lamellar systems were without grana and had dilated intrathylakoid spaces (category 4) in the presence of $30 \mathrm{~m} \mathrm{M} \mathrm{NaCl}$.

Category 3, grana-free lamellar systems amounted to between 1 and 10 per cent, whereas grana-containing lamellar systems

Figure 3. Barley chloroplast lamellar systems of categories 2, 3, and 4 found in preparations isolated with media containing $30 \mathrm{mM} \mathrm{NaCl}$. Category 2 has loosely stacked grana, category 3 is almost devoid of grana and category 4 has dilated intrathylakoid spaces. $x$ 34,000 . 


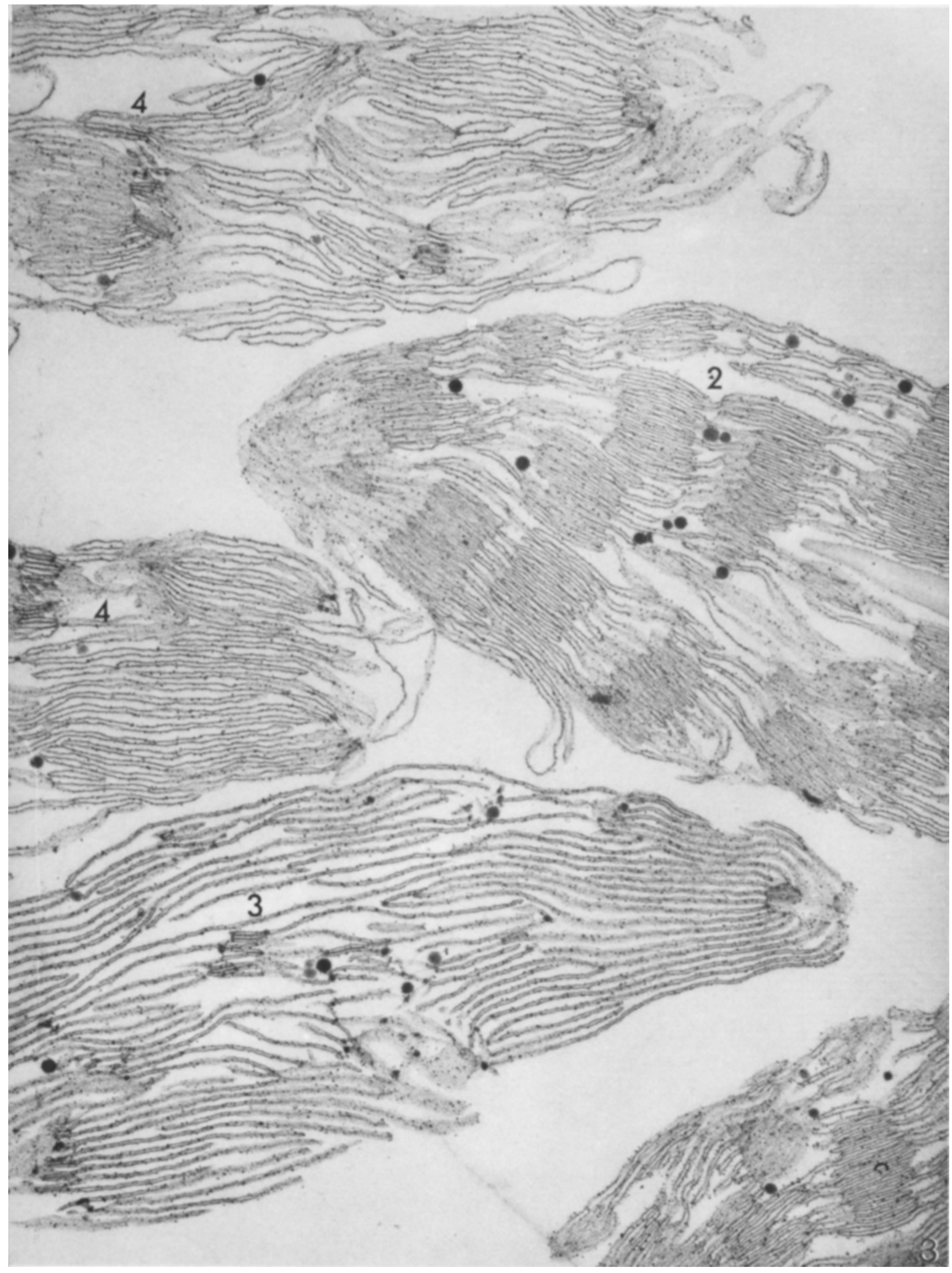


Table II

Activities of chloroplasts prepared in different media

Chloroplast lamellae were prepared, washed, suspended and assayed at $10 \mu \mathrm{g}$ chlorophyll $\mathrm{ml}^{-1}$ in a medium containing $5 \mathrm{mM}$ Tricine- $\mathrm{NaOH}$ pH 7.5,0.05\% (w/v) BSA and the components listed in the table under Medium. 0.33 $\mathrm{mM}$ potassium ferricyanide was also included in the assay medium and where indicated $1 \mu \mathrm{M} 2,5$-dibromo-3methyl-6-isopropyl-p-benzoquinone (DBMIB) and $60 \mathrm{mM}$ methylamine (MA). The samples were illuminated with red light $\left(6.8 \times 10^{5} \mathrm{erg} \mathrm{cm}^{-2} \mathrm{sec}^{-1}\right)$.

\begin{tabular}{|c|c|c|c|c|c|c|}
\hline \multirow[t]{2}{*}{ Medium } & \multicolumn{4}{|c|}{ Ferricyanide Photoreduction } & \multirow{2}{*}{$\frac{+\mathrm{MA}}{-\mathrm{MA}}$} & \multirow{2}{*}{$\begin{array}{c}\text { Inhibition } \\
\text { by DBMIB }\end{array}$} \\
\hline & - & MIB & $+\mathrm{MA}$ & $\begin{array}{l}3 \mathrm{MIB} \\
+\mathrm{MA}\end{array}$ & & \\
\hline $\begin{array}{l}660 \mathrm{mM} \text { sucrose } \\
+30 \mathrm{mM} \mathrm{NaCl}\end{array}$ & 0.56 & $\begin{array}{r}\min ^{-} \\
0.83\end{array}$ & $\begin{array}{r}\text { g Chloro } \\
10.7\end{array}$ & 1.28 & 19.1 & $\begin{array}{r}\% \\
0 \\
88\end{array}$ \\
\hline $\begin{array}{l}330 \mathrm{mM} \text { sucrose } \\
+30 \mathrm{mM} \mathrm{NaCl}\end{array}$ & 0.81 & 1.10 & 11.7 & 1.75 & 14,1 & $\begin{array}{r}0 \\
85\end{array}$ \\
\hline $350 \mathrm{mM} \mathrm{NaCl}$ & 0.71 & 0.65 & 4.77 & 1.43 & 6.7 & $\begin{array}{r}8 \\
70\end{array}$ \\
\hline $30 \mathrm{mM} \mathrm{NaCl}$ & 0.94 & 1.03 & 7.32 & 2.35 & 7.8 & $\begin{array}{r}0 \\
68\end{array}$ \\
\hline
\end{tabular}

amounted to between 20 and 30 per cent. Increasing the temperature from $0 \mathrm{C}$ to $23 \mathrm{C}$, or an illumination with high or medium intensity light did not alter these proportions very much, nor did the substitution of phosphate for Tricine or various other isolation regimes. Including $330 \mathrm{mM}$ or $660 \mathrm{mM}$ sucrose in the 30 $\mathrm{mM} \mathrm{NaCl}$ medium also did nothing to decrease the frequency of grana-free lamellar systems. However, with sucrose the number of category 3 lamellar systems with undilated intrathylakoid spaces was increased.

In agreement with the conclusions reached by IZAWA and GOOD (21) and MURAKAMI and PACKER (31) who used spinach chloroplasts, we found that the concentration of cations determines the amount and frequency of stacking of thylakoids into grana in barley lamellar systems, whereas the osmolarity of the medium to a certain extent determines the width of the intrathylakoid space.

The rates of ferricyanide reduction at saturating light intensities were found to be about the same in these different media (Table II), although somewhat lower at the highest concentration of sucrose. The ferricyanide photoreductive activity is thus independent of the amount and tightness of stacking of thylakoids into grana as well as the thickness of the intrathylakoid spaces. It is remarkable that category 1 of the lamellar systems in $350 \mathrm{mM}$ $\mathrm{NaCl}$ with their tight grana stacking showed similar basic rates of Hill reaction as the granafree lamellar systems of categories 3 and 4 in 30 $\mathrm{mM} \mathrm{NaCl}$ or $30 \mathrm{mM} \mathrm{NaCl}$ plus $330 \mathrm{mM}$ sucrose. The photoreduction of ferricyanide was not inhibited by 3-methyl-6-isopropyl-pbenzoquinone (DBMIB) (Table II) but could be stimulated between 7 - and 20 -fold by the addition of methylamine, a stimulation that was inhibited by DBMIB. This indicates that inhibition by DBMIB was not great enough to make oxidation of plastohydroquinone, the site

Figure 4. Lamellar system of category 2 with grana and dilated, 30 to $60 \mathrm{m \mu}$ thick intrathylakoid spaces. (30 $\mathrm{mM} \mathrm{NaCl}) \times 35,000$.

Figure 5. Category 2 with loosely stacked grana and dilated intrathylakoid spaces. Starch grains are trapped in the lamellar system. $(30 \mathrm{mM} \mathrm{NaCl}) . \times 33,000$.

Figure 6. Category 3 with few residual grana and 15 to $30 \mathrm{m \mu}$ wide intrathylakoid spaces $(30 \mathrm{mM} \mathrm{NaCl}) . \times$ 35,000 . 

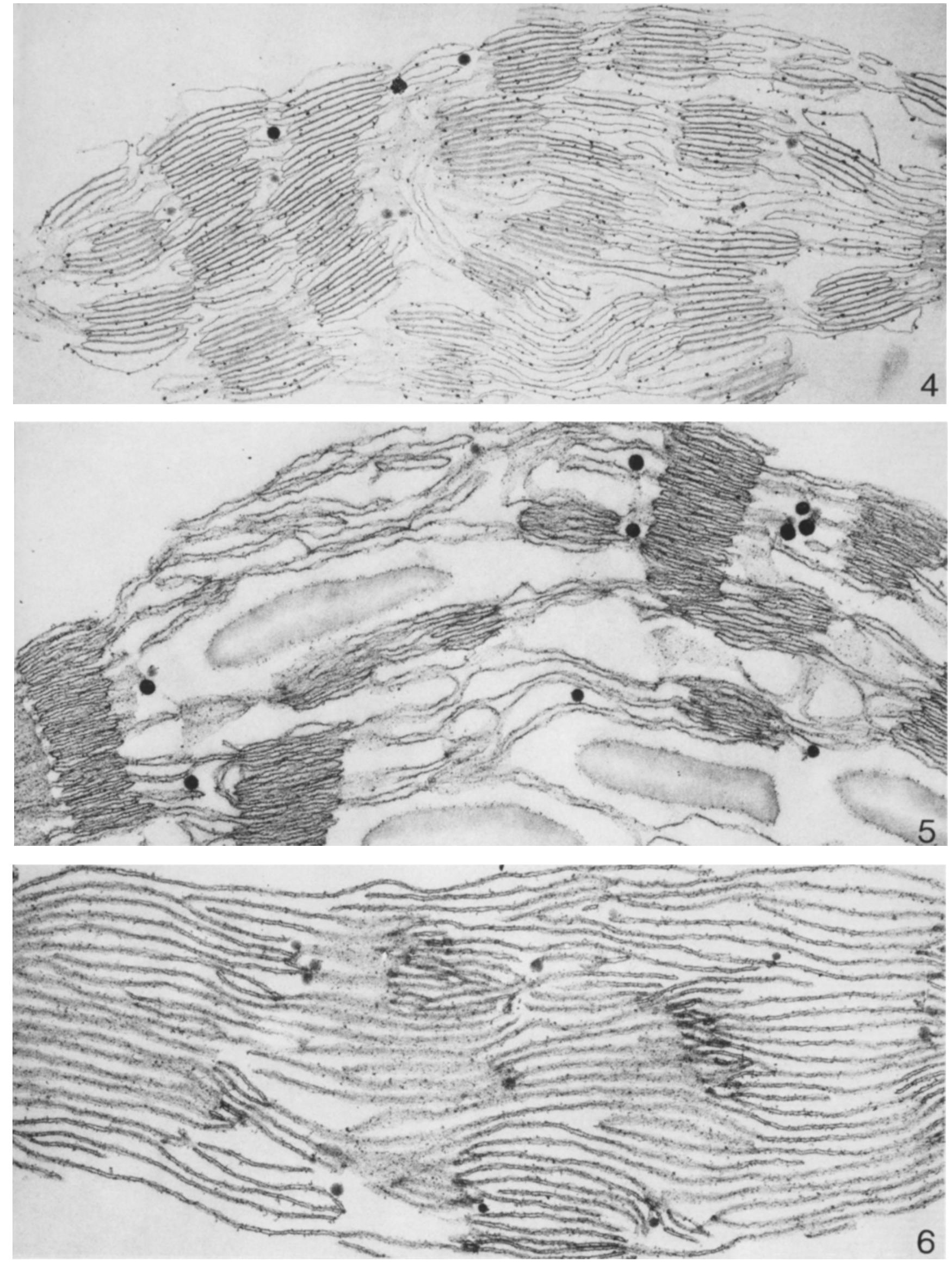
of action of DBMIB (49), the new rate limiting reaction in the coupled chloroplast membranes. In the presence of methylamine the original reaction which limited the rate of ferricyanide photoreduction in the coupled chloroplast membranes was no longer limiting and inhibition of ferricyanide photoreduction by DBMIB could then be observed. The fact that DBMIB inhibited photoreduction of ferricyanide by methylamine-treated thylakoids suggests that these thylakoids were still intact, even though photophosphorylation and proton pump activity were lost. Otherwise it might have been expected that ferricyanide would be reduced at exposed photosystem II sites on the internal surfaces of the thylakoids and DBMIB should not then be inhibitory. The effects of methylamine on the morphology of the barley thylakoids, described below, supports this conclusion in that while methylamine caused gross changes in the appearance of the thylakoids, they nevertheless remained intact.

The effect of methylamine on the morphology of the lamellar systems was uniform (Table VIII) and twofold (Fig. 21 to 24). Methylamine again established appression between adjacent thylakoids in grana-free lamellar systems and reduced the intrathylakoid spaces in many places, especially in the intergrana regions (Fig. 22 and 24 , horizontal arrows). The space was reduced frequently to less than $15 \mathrm{~m} \mu$ and appeared to be eliminated entirely in some places giving some of the intergrana thylakoids a collapsed appearance. The typically net-like appearance of sections through the methylamine-treated lamellar systems (Fig. 21 to 24) is understandable if there were a rapid twofold action of the compound: tight stacking of the grana areas and elimination of intrathylakoid space by membrane association must have lead to a ballooning of some of the intrathylakoid spaces in order to accommodate all of the membrane enclosed solution.

\subsection{The Effect of Low Concentrations of $\mathrm{NaCl}$ and Tricine on the Rate of Photoreduction of Ferricyanide}

In the experiments already described where large rearrangements of thylakoid membranes were shown to take place during isolation of the chloroplasts in different media, the salt concentration was maintained at $30 \mathrm{mM}$ or higher in all media. These membrane rearrangements in the isolated chloroplasts were not accompanied by large changes in photochemical activity (Table II). Typically, 1 to 2 $\mu$ moles ferricyanide photoreduced $\min ^{-1} \mathrm{mg}$ chlorophyll ${ }^{-1}$ were obtained with barley chloroplasts isolated as described in Materials and Methods, washed and suspended in a medium containing $30 \mathrm{mM} \mathrm{NaCl}, 5 \mathrm{mM}$ Tricine- $\mathrm{NaOH}$ pH 2.5 and $0.05 \%$ (w/v) BSA and assayed using the same medium plus $0.33 \mathrm{mM}$ potassium ferricyanide. This rate was increased to 8 to $11 \mu$ moles min $^{-1} \mathrm{mg}$ chlorophyll ${ }^{-1}$ with the addition of methylamine. Maximum stimulation was obtained with $60 \mathrm{mM}$ methylamine, although a 90 per cent stimulation was still obtained with $20 \mathrm{mM}$ methylamine. Reducing the concentration of $\mathrm{NaCl}$ in the presence of $60 \mathrm{mM}$ methylamine did not result in a change in the rate of ferricyanide reduction (Fig. 25). When the concentration of $\mathrm{NaCl}$ was reduced stepwise to below $10 \mathrm{mM}$ in the absence of methylamine, the rate increased progressively showing that the rate of ferricyanide photoreduction was affected by low concentrations of salt (Fig. 25). Since the Tricine buffer contained $\mathrm{Na}^{+}$ions, the effect of varying the Tricine concentration (in the absence of added $\mathrm{NaCl}$ ) on ferricyanide

Figure 7 and 8. Lamellar systems of category 3 with small residual grana and 20 to $30 \mathrm{m \mu}$ wide intrathylakoid spaces. (Fig. 7:30 m M NaCl; Figure 8: 30 $\mathrm{mM} \mathrm{NaCl}$ and $330 \mathrm{mM}$ sucrose). $\times 35,000$.

Figure 9. Category 4 with small residual grana and 30 to $60 \mathrm{m \mu}$ wide, dilated intrathylakoid spaces. $(30 \mathrm{mM}$ $\mathrm{NaCl}) \times 34,000$.

Figure 10 and 11. Granum of category 2 lamellar system with relatively tightly stacked thylakoids in Fig. 10 is compared to granum with loose stacking in Figure 11. Arrow points to separation of the discs in the granum. (30 mM NaCl). $\times 111,000$.

Figure 12 and 13. Comparison of membrane organization of categories 3 and 4 . The intrathylakoid space measures 20 to $30 \mathrm{~m} \mu$ and 30 to $60 \mathrm{~m} \mu$ respectively. (Figure 12: $30 \mathrm{mM} \mathrm{NaCl}$ and $330 \mathrm{mM}$ sucrose; Figure 13: $30 \mathrm{mM} \mathrm{NaCl}) \times 67,000$. 

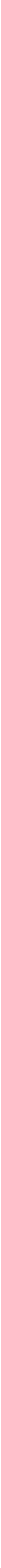

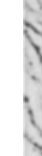

Mi -2

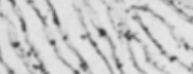

Mit
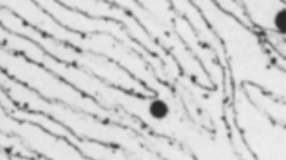

an

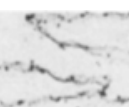



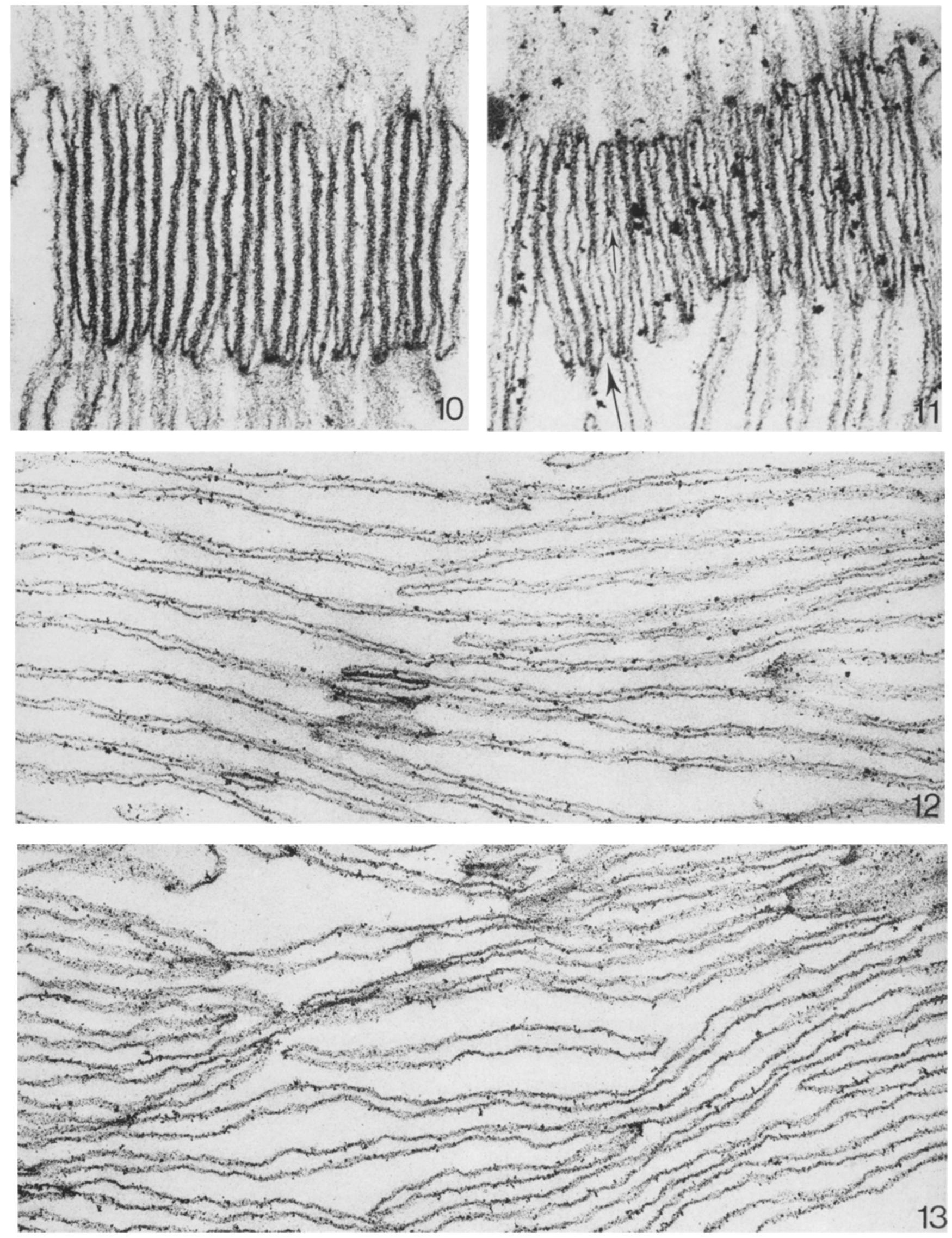
photoreduction was measured (Fig. 26). In this experiment the chloroplast lamellar systems, Tricine buffer $\mathrm{pH} 7.5$, ferricyanide and BSA all were incubated together for $10 \mathrm{~min}$ at $23^{\circ} \mathrm{C}$, and then the sample was illuminated and the rate of ferricyanide reduction determined. At very low Tricine concentrations the rate was less than the rate obtained in the standard reaction mixture $(1.23 \mu$ moles ferricyanide reduced $\mathrm{min}^{-1} \mathrm{mg}$ chlorophyll ${ }^{-1}$ in this experiment). This rate increased as the Tricine concentration was increased, to reach a peak of $4.2 \mu$ moles ferricyanide reduced $\mathrm{min}^{-1} \mathrm{mg}$ chlorophyll ${ }^{-1}$ at $33 \mathrm{mM}$ Tricine. However, the highest rates attained were still well below the uncoupled rate; the addition of $60 \mathrm{mM}$ methylamine in this experiment yielded rates of around $8 \mu$ moles ferricyanide reduced $\mathrm{min}^{-1} \mathrm{mg}$ chlorophyll ${ }^{-1}$ at all concentrations of Tricine employed. Above $33 \mathrm{mM}$, the rate again decreased until the normal rate characteristic of coupled barley chloroplasts was obtained at concentrations in excess of $100 \mathrm{mM}$ Tricine.

This experiment indicated that there could be two distinct effects of cations on ferricyanide photoreduction. As the Tricine (and hence $\mathrm{Na}^{+}$) concentration in the reaction mixture was decreased, the rate of photoreduction increased as might be expected if the chloroplasts were becoming uncoupled as takes place when methylamine is added. Thus salt is evidently required to maintain the chloroplasts in a coupled state. However, the fully uncoupled rate of ferricyanide photoreduction was never attained because of a second effect of the salt, namely, an apparent requirement of salt for Hill activity with ferricyanide. This would have accounted for the peak of activity at $33 \mathrm{mM}$ Tricine. At this concentration of Tricine the chloroplasts behaved as though partially uncoupled. At lower concentrations of Tricine the chloroplasts presumably became even more uncoupled but the rate of ferricyanide photoreduction fell rather than continued to increase because of a salt requirement for this activity. Because two distinct effects of salt on ferricyanide photoreduction were indicated, a way of separating the two effects experimentally was sought, so that each could be studied independently.

\subsection{Cation Requirement for Activation of Ferricyanide Photoreduction}

The requirement of salt for ferricyanide photoreductive activity was studied by exposing barley chloroplasts to a low ionic strength and then adding salt back to the chloroplasts before measuring ferricyanide photoreduction. When the barley chloroplasts were exposed to a sufficiently low concentration of salt the activity approached zero (Table III). The exposure to a low concentration of salt was carried out by diluting the chloroplasts to final concentrations of about $1 \mathrm{mM}$ Tricine and $0.1 \mathrm{mM} \mathrm{NaCl}$

Figure 14. Lamellar system of category 5 with separated and swollen thylakoids. This membrane organization is obtained by resuspension of lamellar systems isolated in $30 \mathrm{mM} \mathrm{NaCl}$ in low salt medium as described in Table III. $\times 26,000$.

Figure 15. Addition of $50 \mathrm{mM} \mathrm{NaCl}$ to lamellar systems of category 5 (see Figure 14 ) results in restacking of the swollen thylakoids (category 6). $\times 15,000$.

Figure 16. Lamellar system of category 6 with grana restacked by the addition of $0.5 \mathrm{mM} \mathrm{MgSO}_{4}$ to lamellar systems of category 5 (see Figure 14). $\times$ 35,000.

Figure 17. Two examples of restacked lamellar systems found in preparations after transfer from medium with $330 \mathrm{mM}$ sucrose and $30 \mathrm{mM} \mathrm{NaCl}$ to low salt medium as described in Table III, except that $330 \mathrm{mM}$ sucrose was always present, and thereafter an addition of $0.5 \mathrm{mM}$ $\mathrm{MgSO}_{4}$. At left is a category 2 lamellar system, which is considered to have not been grossly swollen and deranged by the low salt treatment. At right restacking of category 4 (cf. Figure 9) lamellar system. $\times$ 29,000 .

Figure 18 to 20. Details of restacked membranes by addition of $50 \mathrm{mM} \mathrm{NaCl}$ to lamellar systems in low salt medium (see Fig. 15). $\times 57,000$.

Figure 21. Lamellar systems of category 7 obtained by addition of $60 \mathrm{mM}$ methylamine to lamellar systems isolated in media containing $30 \mathrm{mM} \mathrm{NaCl}$. Sections of these lamellar systems display a netlike configuration. $\times 18,000$.

Figure 22 to 24 . Membrane organization after adding 60 $\mathrm{mM}$ methylamine to lamellar systems isolated in $30 \mathrm{mM}$ $\mathrm{NaCl}$ (Figure 24 for $30 \mathrm{mM} \mathrm{NaCl}$ and $330 \mathrm{mM}$ sucrose (Figure 22 and 23). Methylamine enhances and reestablishes tight stacking of thylakoids into grana (vertical arrows). It reduces intrathylakoid spaces of stroma thylakoids frequently to less than $10 \mathrm{~m} \mu$ (horizontal arrows) and sometimes eliminates this space entirely. 


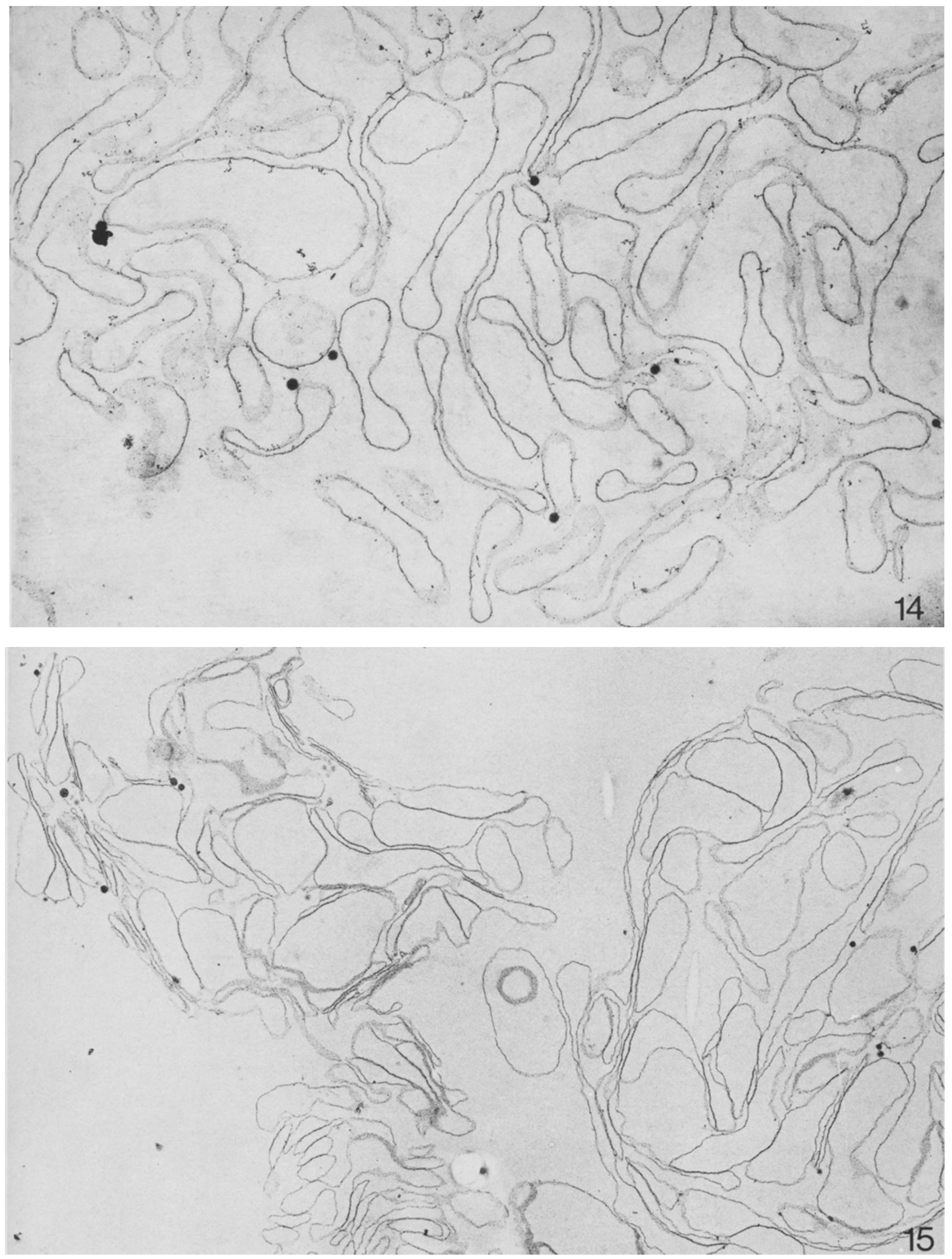



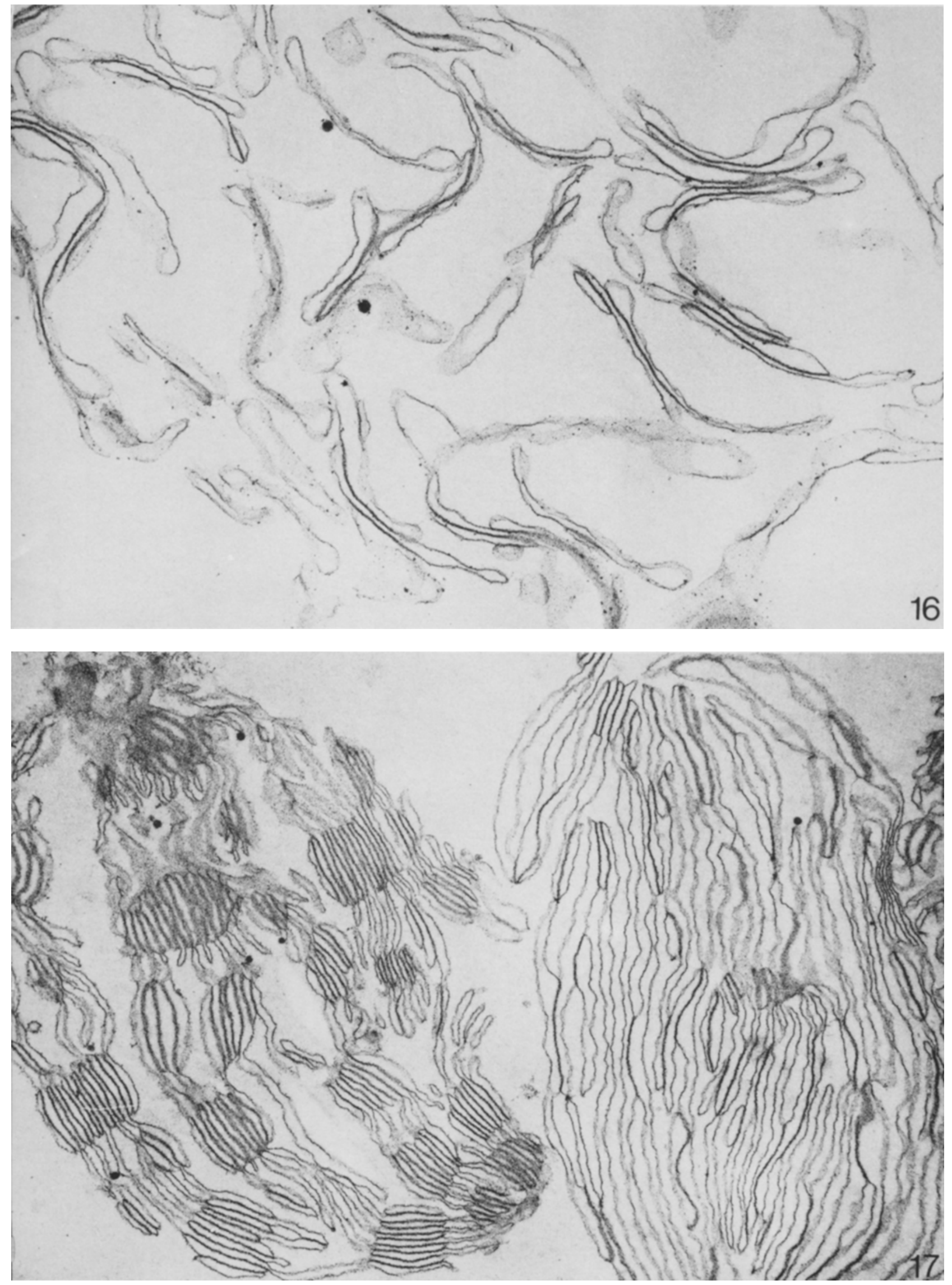

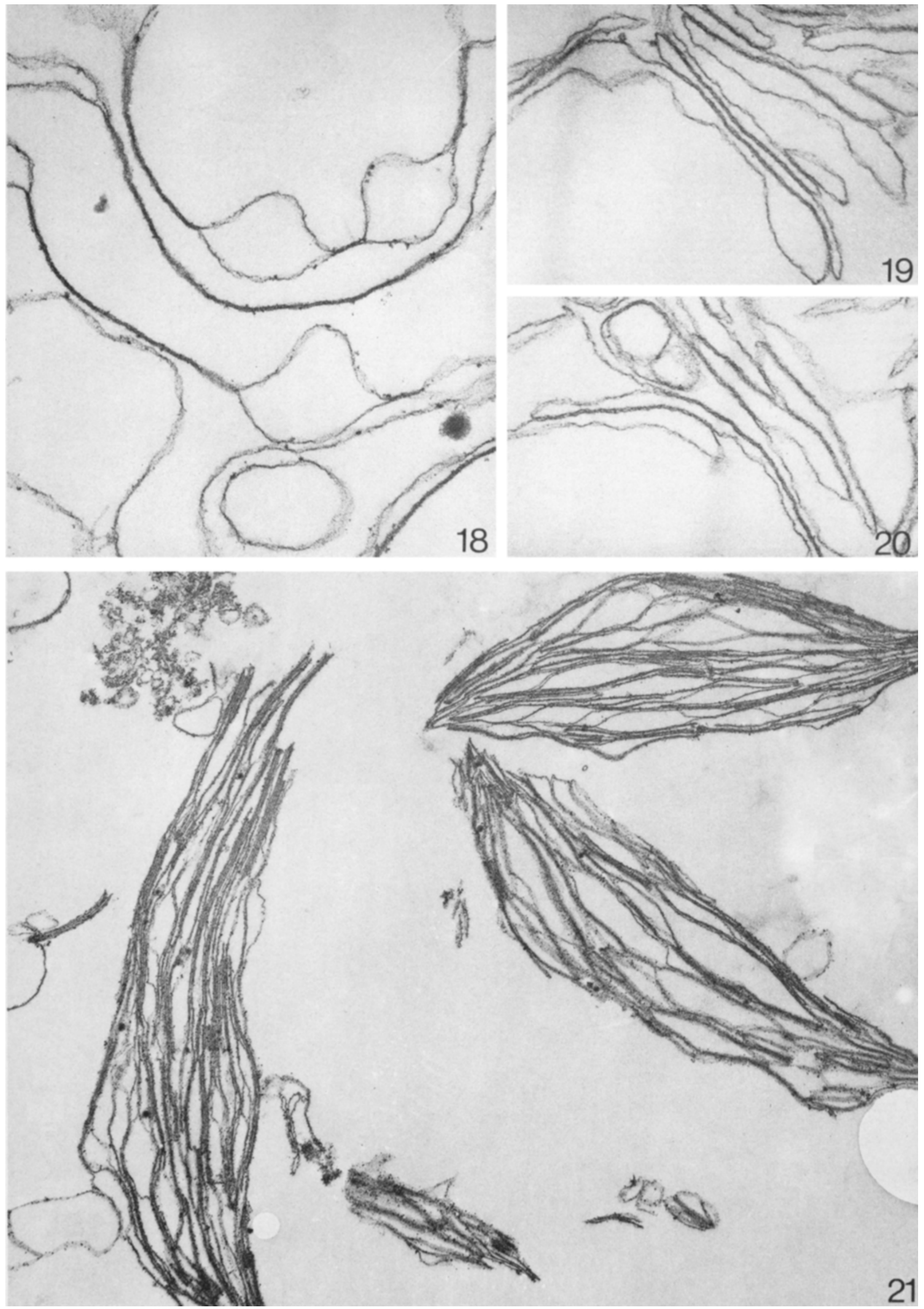

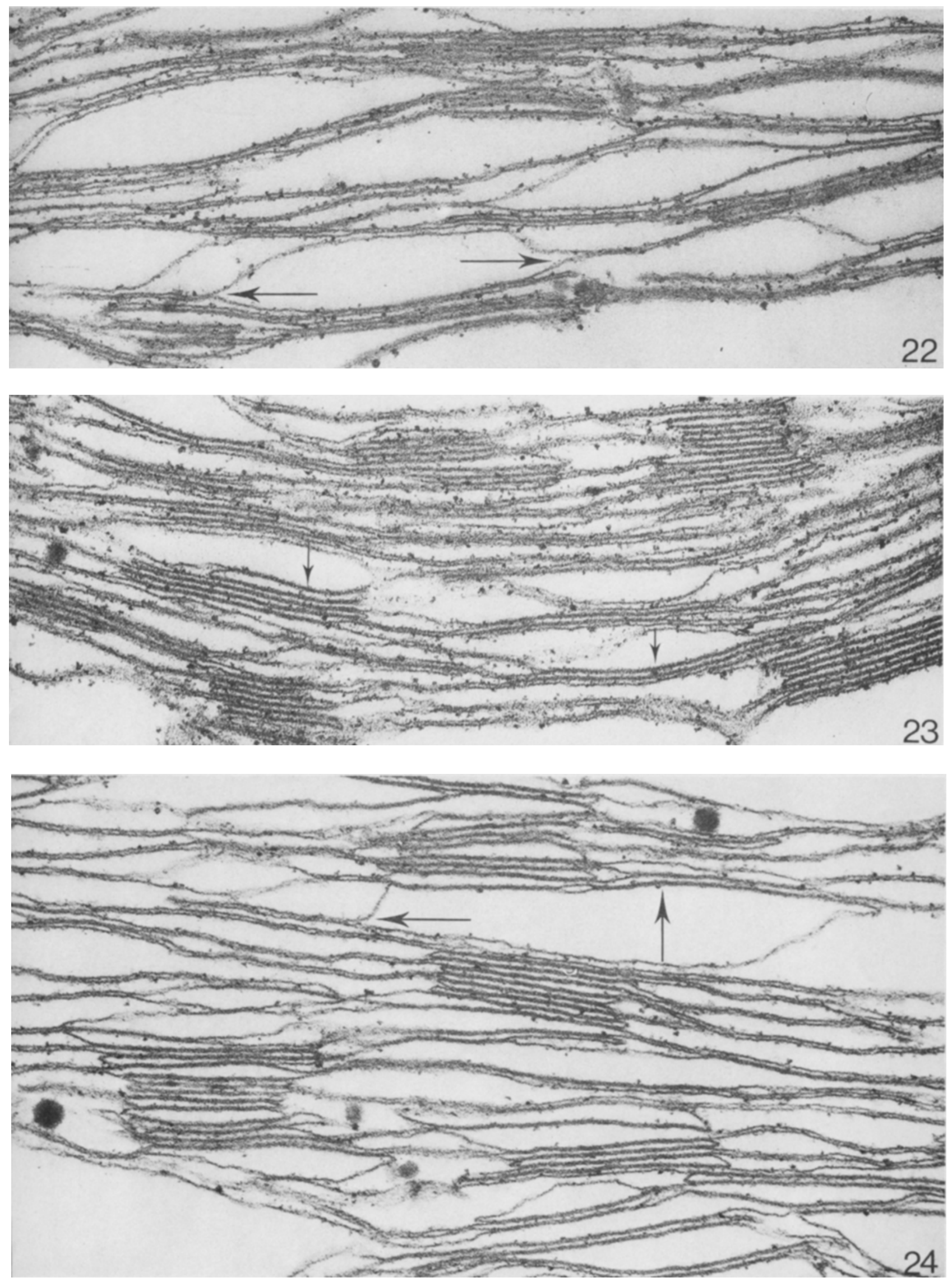


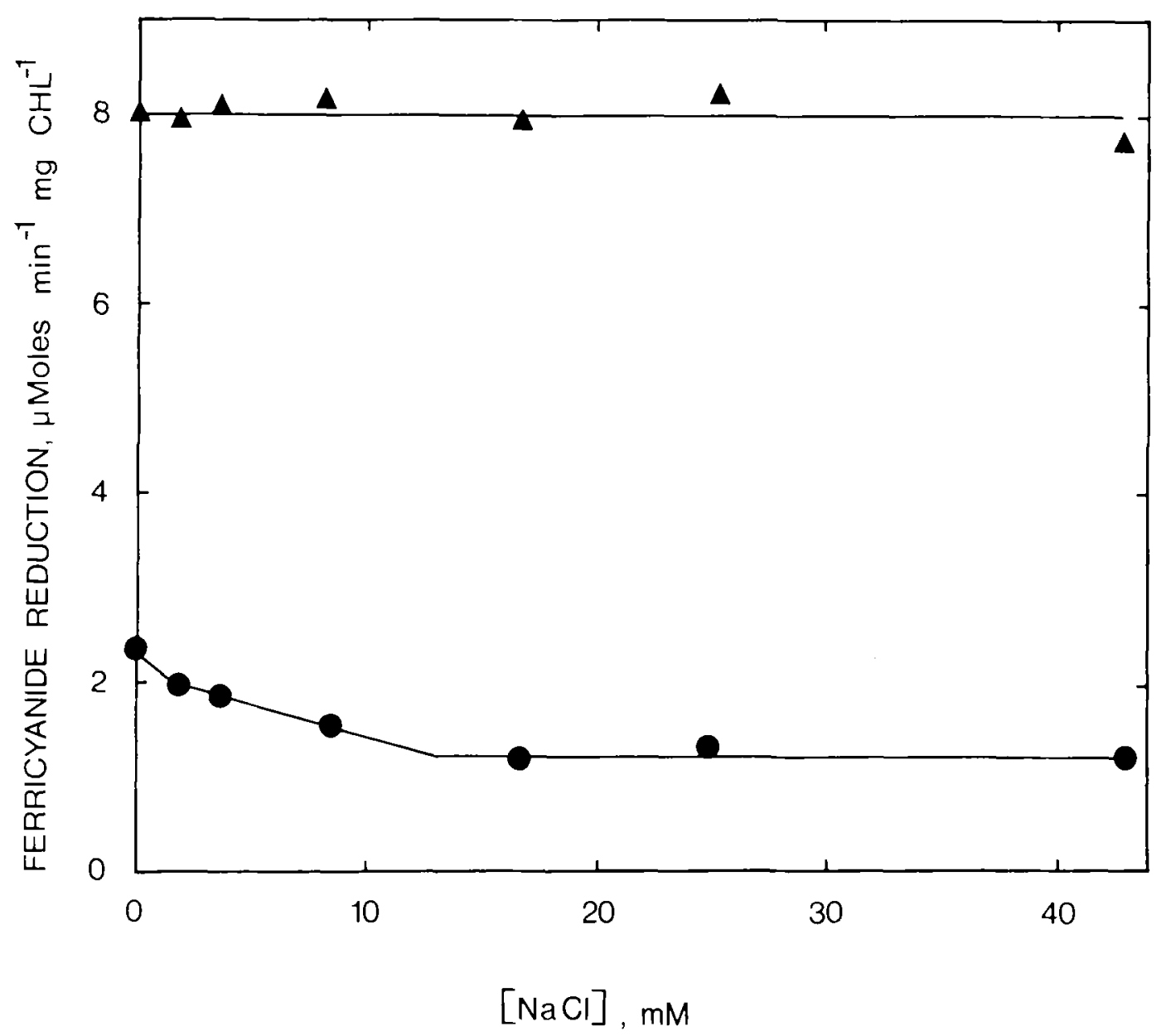

Figure 25. Photoreduction of ferricyanide by barley chloroplast lamellae in the presence of different concentrations of $\mathrm{NaCl}$. The chloroplast lamellae (10 $\mathrm{\mu g}$ chlorophyll $\mathrm{ml}^{-1}$ ) were incubated for $5 \mathrm{~min}$ at $23^{\circ} \mathrm{C}$ in a reaction mixture containing $50 \mathrm{mM}$ Tricine $\mathrm{pH} 7.5$, $0.33 \mathrm{mM}$ potassium ferricyanide, $0.05 \%(w / v) \mathrm{BSA}$ and $\mathrm{NaCl}$ as indicated. The reaction mixture was then illuminated and ferricyanide reduction measured at $23^{\circ} \mathrm{C}$ - - , rate in absence of methylamine; — $-60 \mathrm{mM}$ methylamine added to reaction mixture immediately before illumination.

and incubating for $15 \mathrm{~min}$ at $23^{\circ} \mathrm{C}$. The BSA concentration was maintained at $0.05 \%(\mathrm{w} / \mathrm{v})$. If $\mathrm{KCl}$ (or $\mathrm{NaCl}$ ) was added to the reaction mixture just prior to measuring the rate of ferricyanide photoreduction, activity was regained, but the rate was no longer the same as the original one but now corresponded to the uncoupled rate given in the presence of methylamine (Table III). The treatment with a low concentration of salt appeared both to un- couple the chloroplasts and inactivate ferricyanide photoreduction, but photoreduction could again be demonstrated if excess $\mathrm{KCl}$ (or $60 \mathrm{mM}$ methylamine) was added to the reaction mixture. Maximum activation of ferricyanide photoreduction by $\mathrm{KCl}$ was obtained within $0.5 \mathrm{~min}$. Similar results to those shown in Table Ill were obtained using 2,6dichlorophenol indophenol as the electron acceptor instead of ferricyanide.

Figure 27 shows the activation of ferricyanide photoreduction obtained by various concentrations of $\mathrm{KCl}$ or $\mathrm{MgCl}_{2}$ after first exposing the chloroplast lamellae to a low concentration of salt. Maximum activation was obtained with about either $30 \mathrm{mM} \mathrm{KCl}$ or $3 \mathrm{~m} \mathrm{M} \mathrm{MgCl}_{2}$. The effect was due to the cations present since $\mathrm{KCl}$, $\mathrm{KNO}_{3}, \mathrm{~K}_{2} \mathrm{SO}_{4}$ and $\mathrm{NaCl}$ all behaved similarly at saturating (Table IV) or intermediate concentrations while approximately only one-tenth 


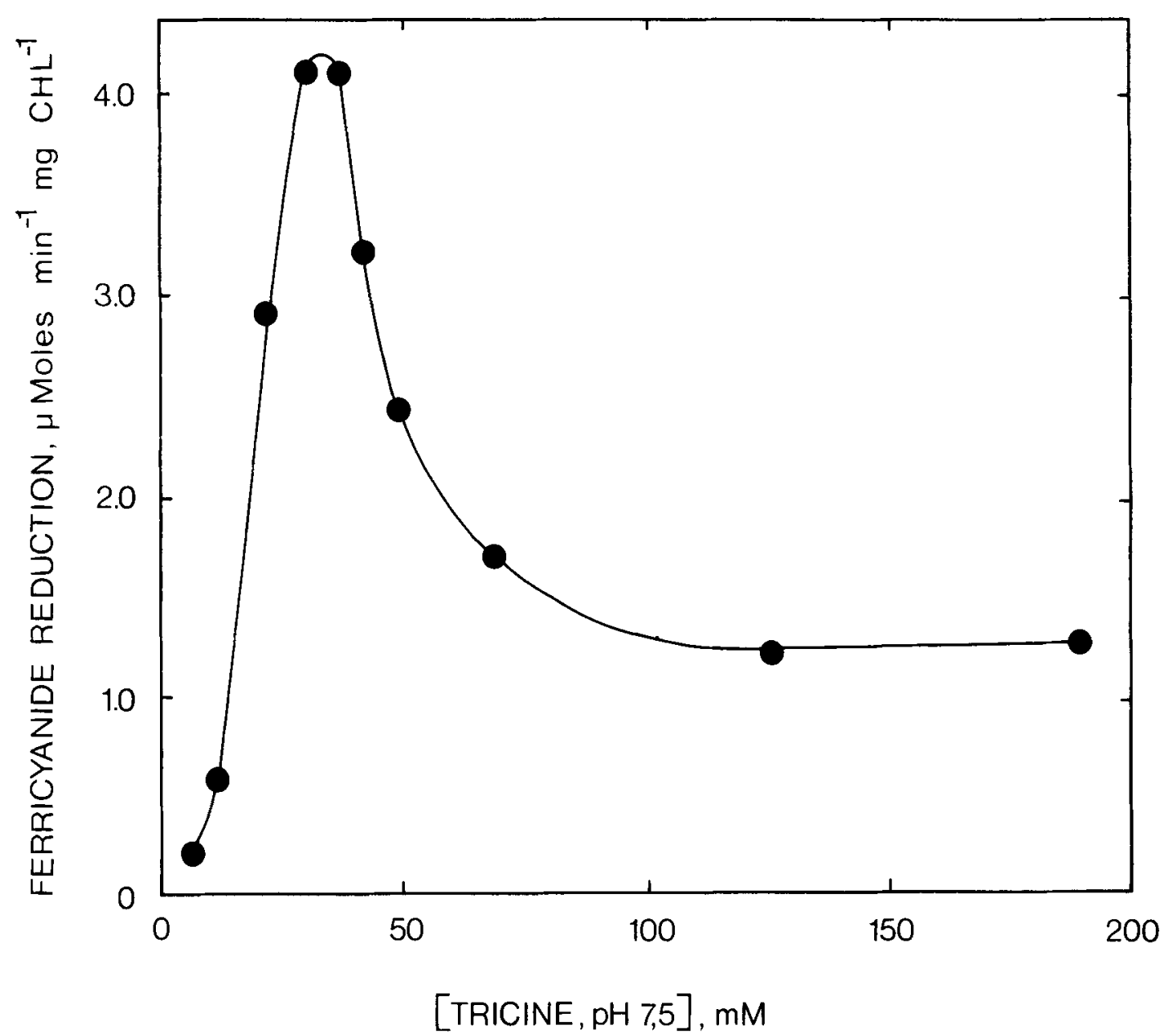

Figure 26. The effect of the Tricine concentration on photoreduction of ferricyanide. Barley chloroplast lamellar systems prepared as described in Materials and Methods were diluted to $10 \mu \mathrm{g}$ chlorophyll $\mathrm{ml}^{-1}$ in reaction mixtures containing in final concentrations potassium ferricyanide, $0.33 \mathrm{mM}, \mathrm{BSA}$, $0.05 \%(\mathrm{w} / \mathrm{v})$ and Tricine- $\mathrm{NaOH}$ buffer $\mathrm{pH} 7.5$ as indicated in the figure. The concentration of residual $\mathrm{NaCl}$ carried over into the reaction mixture with the chloroplast lamellae was $0.12 \mathrm{mM}$. After $10 \mathrm{~min}$ at $23^{\circ} \mathrm{C}$, the reaction mixture was illuminated and ferricyanide photoreduction measured at $23^{\circ} \mathrm{C}$.

of the cation concentration was required when $\mathrm{K}^{+}$was replaced by divalent cations such as $\mathrm{Mg}^{++}, \mathrm{Ca}^{++}$, or $\mathrm{Mn}^{++}$.

\subsection{Cation Requirements for Preservation of Thylakoid Membrane Integrity}

Besides a requirement for activation of ferricyanide photoreduction, cations were also necessary to preserve the rate of ferricyanide photoreduction characteristic of coupled barley chloroplasts. This latter requirement could be seen as an increase in rate of ferricyanide photoreduction due to an apparent uncoupling effect as the cation concentration was decreased, and this was accompanied by extensive swelling of the thylakoid membranes (see below). Measurement of the activity changes resulting from this particular cation effect was complicated by the cation requirement discussed above for photoreductive activity per se which was superimposed upon it (Fig. 26). Presumably, as the thylakoids became swollen at low cation concentrations, thylakoid integrity was lost and ions leaked from the intrathylakoid spaces resulting in the appearance of a cation requirement for ferricyanide photoreduction. This complication was 


\section{Table III}

Activation of ferricyanide photoreduction by $\mathrm{KCl}$ following the exposure of chloroplast lamellae to a low concentration of salt.

Barley chloroplast lamellar systems were prepared as described in Materials and Methods and exposed to low salt conditions by diluting them to $10 \mu \mathrm{g}$ chlorophyll $\mathrm{ml}^{-1}$ with a medium to give a final concentration of $0.12 \mathrm{mM} \mathrm{NaCl}, 1.2 \mathrm{mM}$ Tricine $\mathrm{pH} 7.5$ and $0.05 \%(\mathrm{w} / \mathrm{v}) \mathrm{BSA}$. After $15 \mathrm{~min}$ at $23^{\circ} \mathrm{C}, 0.33 \mathrm{mM}$ potassium ferricyanide and $33 \mathrm{mM} \mathrm{KCl}$ were added and ferricyanide photoreduction measured immediately at $23^{\circ} \mathrm{C}$. Where indicated in the table, 60 $\mathrm{mM}$ methylamine or $6.7 \mu \mathrm{M}$ DCMU were added also just prior to illuminating the chloroplasts. Untreated chloroplasts were assayed in a reaction mixture containing chloroplast lamellae $\left(10 \mu \mathrm{g}\right.$ chlorophyll $\left.\mathrm{ml}^{-1}\right)$, $30 \mathrm{mM} \mathrm{NaCl}, 5 \mathrm{mM}$ Tricine pH 7.5, 0.05\% (w/v) BSA and $0.33 \mathrm{mM}$ potassium ferricyanide.

\begin{tabular}{|c|c|}
\hline $\begin{array}{l}\text { Additions to } \\
\text { Reaction Mixture }\end{array}$ & $\begin{array}{c}\text { Rate of Photoreduction } \\
\text { of Ferricyanide }\end{array}$ \\
\hline & umoles min $^{-1} \mathrm{mg}$ Chlorophyll ${ }^{-1}$ \\
\hline \multicolumn{2}{|l|}{ Untreated chloroplasts } \\
\hline None & 1.2 \\
\hline Methylamine & 11.3 \\
\hline Chloroplasts exposed to & \\
\hline low salt conditions & \\
\hline None & 0.15 \\
\hline Methylamine & 11.1 \\
\hline $\mathrm{KCl}$ & 11.0 \\
\hline $\mathrm{KCl}+$ Methylamine & 11.1 \\
\hline $\mathrm{KCl}+\mathrm{DCMU}$ & 0 \\
\hline
\end{tabular}

circumvented by first treating the chloroplasts with low concentrations of cations and then determining the effect of this treatment on the capacity for ferricyanide photoreduction by supplying an excess amount of cations prior to measuring the activity.

Figure 28 shows that the cation requirement for preservation of the coupled state in barley chloroplasts is a time-dependent one. When the chloroplasts were incubated at $23^{\circ} \mathrm{C}$ in a low concentration of salt there was a loss of activity, as was previously shown in Table III. However, if excess $\mathrm{NaCl}$ was added just prior to measuring the rate of fericyanide photoreduction, the rate increased with time of incubation in the low concentration of salt. Although not shown in this figure, there was no appreciable change of activity when the incubation at $23^{\circ} \mathrm{C}$ was carried out in the presence of $33 \mathrm{mM} \mathrm{NaCl}$. The increase in the rate of ferricyanide photore- duction with time suggests that the chloroplasts were becoming progressively uncoupled. After $5 \mathrm{~min}$ at $23^{\circ} \mathrm{C}$ the chloroplast lamellae were 82 per cent uncoupled (relative to the initial "coupled" rate) and it took $10 \mathrm{~min}$ of incubation under conditions of low salt for the chloroplast lamellae to attain the same rate of photoreduction as chloroplasts uncoupled by methylamine. This time factor has to be taken into account in studies of cation effects on the Hill activity of chloroplasts.

Figure 29 shows the effect of the concentration of $\mathrm{KCl}$ or $\mathrm{MgCl}_{2}$ on the preservation of the coupled state in barley chloroplast membranes. The chloroplasts were diluted and incubated at $23^{\circ} \mathrm{C}$ as described for Figure 28, except that all incubations were for $15 \mathrm{~min}$ and were carried out in the presence of different concentrations of $\mathrm{KCl}$ or $\mathrm{MgCl}_{2}$. Excess $\mathrm{KCl}$ was added to all reaction mixtures at the end of the $15 \mathrm{~min}$ incubation period and prior to measuring ferricyanide photoreduction. When concentrations above about $10 \mathrm{mM} \mathrm{KCl}$ or $40 \mu \mathrm{M}$ $\mathrm{MgCl}_{2}$ were used during the $15 \mathrm{~min}$ incubation period the rates obtained were the same as those shown by the coupled chloroplasts. As the cation concentrations were decreased below these values the rate of ferricyanide photoreduction increased to the same rate exhibited by fully uncoupled chloroplasts (determined in the presence of $60 \mathrm{mM}$ methylamine). A peak of activity at a particular cation concentration as had been found with Tricine in Figure 26 was not obtained because excess $\mathrm{KCl}$ was added at the end of the incubation period at $23^{\circ} \mathrm{C}$ to provide the cations necessary for ferricyanide photoreductive activity. As in the case of salt activation of ferricyanide photoreduction, the salt effect on preservation of the coupled state in the chloroplasts was also a cation effect (Table V) and monovalent cations were far less effective than divalent cations.

The concentrations of cations required for the two cation effects on ferricyanide photoreduction are compared in Table VI. The concentration of $\mathrm{K}^{+}$ions required for 50 per cent activation of photoreduction in chloroplasts uncoupled by a low salt treatment was more than double the concentration required to keep the 


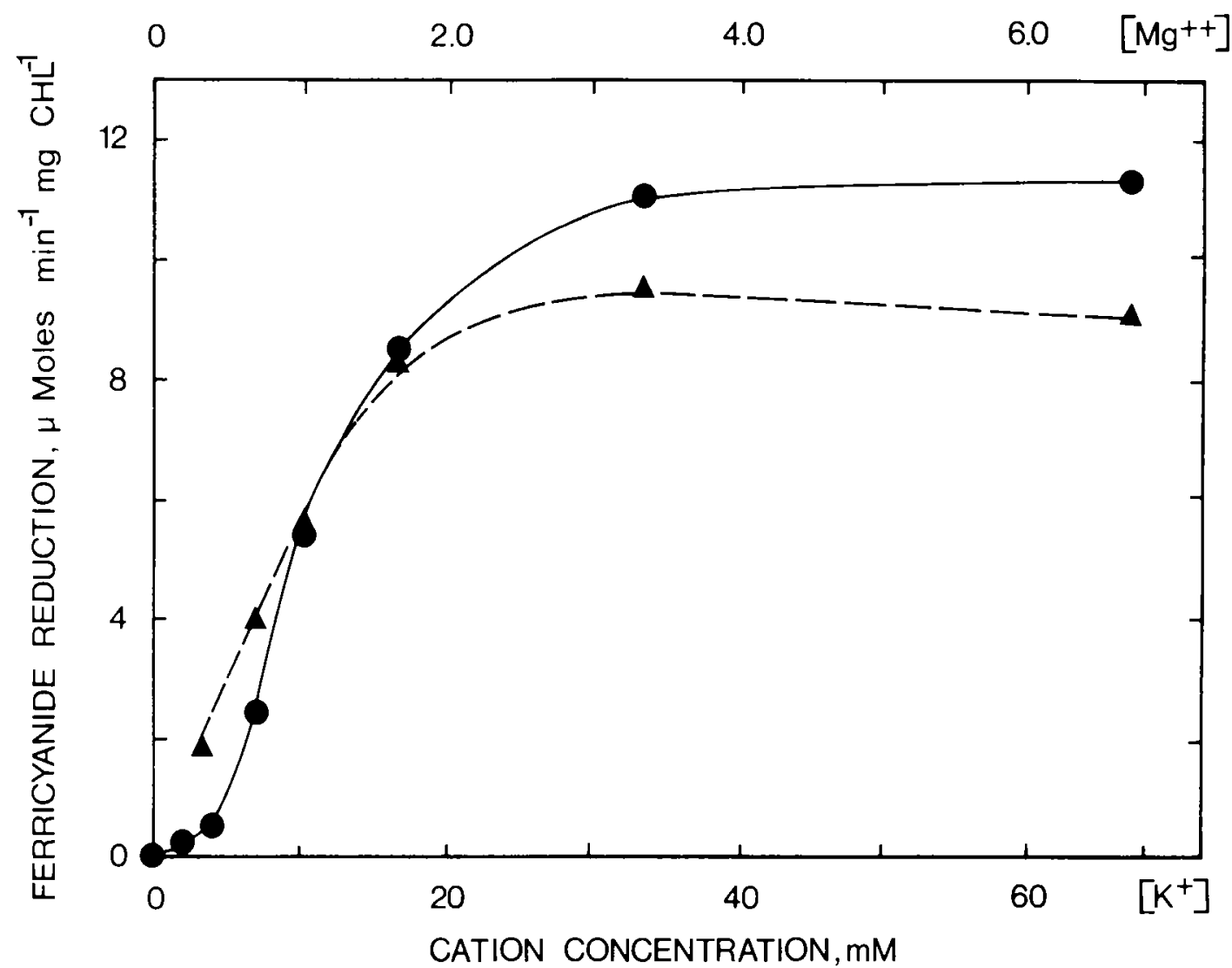

Figure 27. Activation of ferricyanide photoreduction by $\mathrm{KCl}$ or $\mathrm{MgCl}_{2}$. Chloroplast lamellae were exposed to a low concentration of salt as described in Table III and $\mathrm{KCl}$ or $\mathrm{MgCl}_{2}$ added just prior to illuminating the samples and measuring ferricyanide photoreduction. Details of the experimental procedure are given in Table III. - $\bullet, \mathrm{NaCl} ; \bullet-\triangle \mathrm{MgCl}_{2}$.

chloroplasts in coupled state. For $\mathbf{M g}^{++}$ions around 40 times as much was necessary. The relative effectiveness of these two ions for each of the cation effects was also markedly different. The divalent ion was more than 200 times as effective as the monovalent ion for maintenance of a coupled state, whereas it was only 12 times as effective in activating ferricyanide photoreduction. The concentrations for 50 per cent cation effectiveness given in Table VI are minimal values since to these concentrations should be added the small concentrations of cations already present in the reaction mixture. The sources of these additional cations were the $1.2 \mathrm{mM}$ Tricine $\mathrm{NaOH}$ buffer and the BSA and $\mathrm{NaCl}$ carried
Table IV

Activation of ferricyanide photoreduction by various cations following the exposure of chloroplast lamellae to a low concentration of salt.

The experimental procedure is given in Table III.

\begin{tabular}{|c|c|c|}
\hline \multicolumn{2}{|c|}{$\begin{array}{l}\text { Additions to Reaction } \\
\text { Mixture }\end{array}$} & \multirow[t]{2}{*}{$\begin{array}{l}\text { Rate of Photoreduction } \\
\text { of Ferricyanide }\end{array}$} \\
\hline Salt & $\begin{array}{l}\text { Concen- } \\
\text { tration }\end{array}$ & \\
\hline $\begin{array}{l}\text { None } \\
\mathrm{KCl} \\
\mathrm{NaCl} \\
\mathrm{KNO}_{3} \\
\mathrm{~K}_{2} \mathrm{SO}_{4}\end{array}$ & $\begin{array}{c}m M \\
- \\
33 \\
33 \\
33 \\
16\end{array}$ & $\begin{array}{c}\text { umoles } \text { min }^{-1} \mathrm{mg} \text { Chlorophyll } \\
0.17 \\
10.9 \\
11.0 \\
10.2 \\
9.8\end{array}$ \\
\hline $\begin{array}{l}\mathrm{CaCl}_{2} \\
\mathrm{CaCl}_{2} \\
\mathrm{MgCl}_{2} \\
\mathrm{MnCl}_{2}\end{array}$ & $\begin{array}{l}3.3 \\
1.0 \\
1.0 \\
1.0\end{array}$ & $\begin{array}{r}10.3 \\
6.4 \\
5.7 \\
5.2\end{array}$ \\
\hline
\end{tabular}




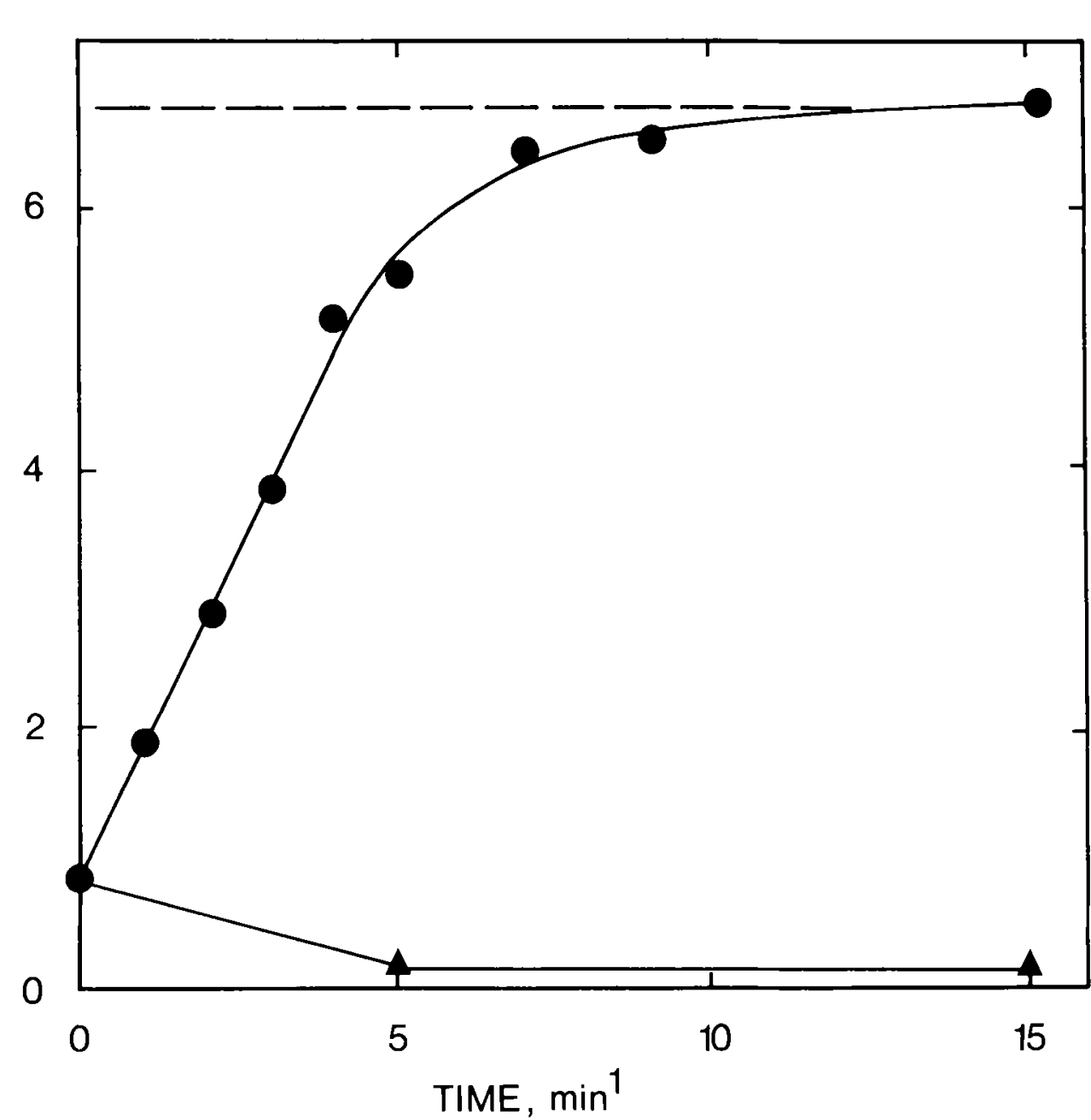

Figure 28. Changes in ferricyanide photoreduction activity after exposing chloroplast lamellae for various times to a low concentration of salt. Chloroplast lamellae prepared as described in Materials and Methods were diluted and held at $23^{\circ} \mathrm{C}$ for the various periods of time indicated in the figure. During this incubation period concentrations were as follows: chlorophyll, $10 \mu \mathrm{g} \mathrm{ml}^{-1} ; \mathrm{NaCl} 0.7 \mathrm{mM}$; Tricine- $\mathrm{NaOH}$ ph 7.5, 1.2 $\mathrm{mM}$; and BSA, $0.05 \%(\mathrm{w} / \mathrm{v})$. At the end of each time period a mixture of $\mathrm{NaCl}$ and potassium ferricyanide to final concentrations $33 \mathrm{mM}$ and $0.33 \mathrm{mM}$, respectively, was added. The sample was illuminated and the rate of photoreduction of ferricyanide measured. --. as above; $\boldsymbol{-} \_-.33 \mathrm{mM} \mathrm{NaCl}$ was not added following the incubation at $23^{\circ} \mathrm{C}$. The dotted line indicates the activity obtained when 60 $\mathrm{mM}$ methylamine was added to the reaction mixture just before illuminating the sample. over during dilution of the chloroplasts $(0.7$ $\mathrm{mM} \mathrm{NaCl}$ and $0.12 \mathrm{mM} \mathrm{NaCl}$ respectively, for preservation of coupled activity and ferricyanide photoreduction activation) and in the case of the activation measurements only, $1.0 \mathrm{mM} \mathrm{K}^{+}$from the potassium ferricyanide.

Under our assay conditions the photoreduction of ferricyanide approached light saturation at irradiances of 5 to $10 \times 10^{4}$ ergs cm-2 $\mathrm{sec}^{-1}$ of red light. When ferricyanide photoreduction was assayed in the presence of $60 \mathrm{mM}$ methylamine or $0.1 \mathrm{mM}$ p-phenylenediamine, a photosystem II acceptor, light saturation was not approached until irradiances in excess of 35 $\times 10^{4}$ ergs $\mathrm{cm}^{-2} \mathrm{sec}^{1}$ were exceeded (unpublished results). Below this there was a linear relationship between the rate of ferricyanide photoreduction and the irradiance. 


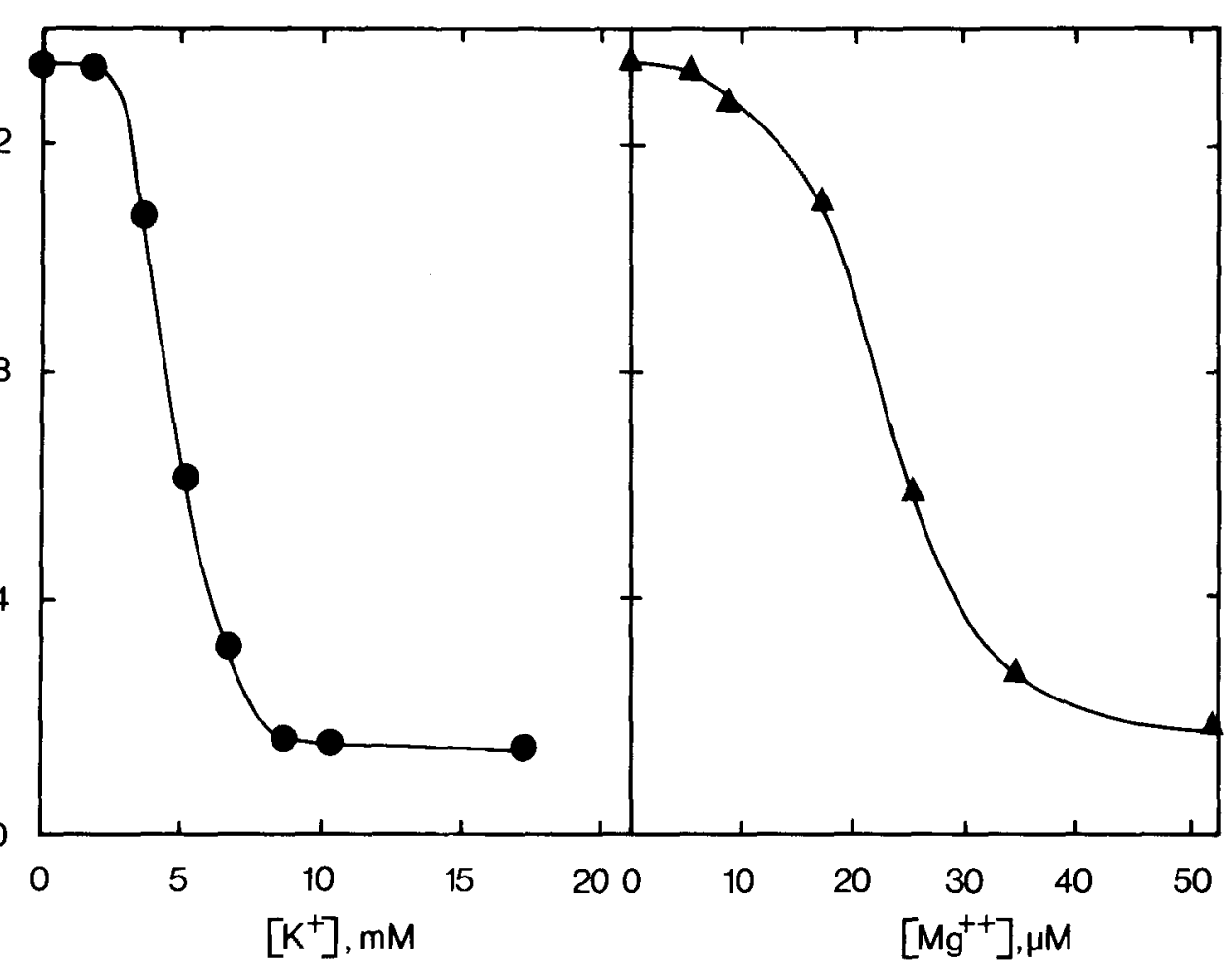

Figure 29. Effect of various concentrations of $\mathrm{KCl}$ and $\mathrm{MgCl}_{2}$ on the coupled state in chloroplast lamellae. The experiment was carried out as described in Fig. 28 except that various concentrations of either $\mathrm{KCl}$ or $\mathrm{MgCl}_{2}$ were included during the incubation period at $23^{\circ} \mathrm{C}$ and this period was $15 \mathrm{~min}$ in every case. $33 \mathrm{mM}$ $\mathrm{KCl}$ instead of $\mathrm{NaCl}$ was added at the end of the 15 min incubation period. - - chloroplasts incubated for $15 \mathrm{~min}$ in the presence of different concentrations of $\mathrm{KCl}$; $\Delta-\Delta$, chloroplasts incubated for $15 \mathrm{~min}$ in the presence of different concentrations of $\mathrm{MgCl}_{2}$.

Chloroplasts exposed to a low salt treatment for $15 \mathrm{~min}$ as described in Figure 29 behaved exactly like untreated chloroplasts uncoupled by 60 $\mathrm{mM}$ methylamine when ferricyanide photoreduction was measured (in the presence of excess $\mathrm{NaCl}$ or $\mathrm{KCl}$ ) as a function of the ir-radiance. JAGENDORF and SMITH (23) and SPENCER and UNT (46) have also noted changes in the activity of ferricyanide photoreduction versus light intensity in cation-depleted chloroplasts.
Table V

Cations and thylakoid membrane integrity:

Retention of coupled activity by incubation with various cations.

For experimental procedure see Fig. 29.

\begin{tabular}{l|c|c}
\hline \multicolumn{2}{l|}{$\begin{array}{l}\text { Salt Present During } \\
\text { I5 min Pre-incubation }\end{array}$} & $\begin{array}{c}\text { Rate of Photoreduction } \\
\text { of Ferricyanide in Presence } \\
\text { of an Excess of } \mathrm{KCl} \\
(33 \mathrm{mM})\end{array}$ \\
\hline Salt & $\begin{array}{c}\text { Concen- } \\
\text { tration }\end{array}$ & \\
\hline & $m M$ & umoles min $^{-1}$ mg chlorophyll \\
& - & 13.4 \\
$\mathrm{None}$ & 6.9 & 3.2 \\
$\mathrm{KCl}$ & 10.3 & 1.5 \\
$\mathrm{KCl}$ & 6.9 & 3.5 \\
$\mathrm{NaCl}$ & 10.3 & 1.6 \\
$\mathrm{NaCl}_{\mathrm{KNO}}$ & 6.9 & 3.3 \\
$\mathrm{KNO}_{3}$ & 10.3 & 1.5 \\
$\mathrm{~K}_{2} \mathrm{SO}_{4}$ & 5.1 & 2.1 \\
$\mathrm{CaCl}_{2}$ & 0.05 & 2.1 \\
$\mathrm{MgCl}_{2}$ & 0.05 & 1.9 \\
$\mathrm{MnCl}_{2}$ & 0.05 & 1.9 \\
\hline
\end{tabular}


Table VI

Relative effectiveness of monovalent and divalent cations.

\begin{tabular}{l|c|c}
\hline Cation & $\begin{array}{c}\text { Retention of } \\
\text { Coupled } \\
\text { Activity }\end{array}$ & $\begin{array}{c}\text { Cation Activation } \\
\text { of Ferrycyanide } \\
\text { Photoreduction }\end{array}$ \\
\hline $\begin{array}{c}\text { mM Cation } \\
\text { Concentration } \\
\text { for } \\
\mathrm{K}^{+}\end{array}$ & $\begin{array}{c}\text { mM Cation } \\
\text { Required } \\
\text { for } \\
\mathrm{Mg}^{+}\end{array}$ & $\begin{array}{c}\text { of Activity } \\
4.6 \\
0.022\end{array}$ \\
\hline$\left[\mathrm{K}^{+}\right] /\left[\mathrm{Mg}^{++}\right]$ & 209 & $\begin{array}{c}50 \% \text { Activation } \\
10.4 \\
0.86\end{array}$ \\
\hline
\end{tabular}

\section{Table VII}

The effect of low cation concentration on light-dependent $\mathrm{pH}$ changes.

Chloroplast lamellae were prepared as described in Materials and Methods except that the lamellae were suspended in $34 \mathrm{mM} \mathrm{NaCl}, 2.5 \mathrm{mM}$ Tricine $\mathrm{pH} 7.5$ and $0.05 \%(\mathrm{w} / \mathrm{v})$ BSA (treatment 1$)$. In the "low salt * treatment, the chloroplast lamellae were incubated for $15 \mathrm{~min}$ at $23^{\circ} \mathrm{C}$ (treatment 2), as described in Fig. 29 , and then assayed. For treatment 3 in the table, $\mathrm{NaCl}$ to final concentration of $35 \mathrm{mM}$ was added to a portion of the chloroplast lamellae from treatment 2 immediately after the $15 \mathrm{~min}$ incubation. To uncouple the chloroplast lamellae used in treatment $1,6 \mathrm{mM}$ $\mathrm{NH}_{4} \mathrm{Cl}$ was added to the reaction mixture for the $\Delta \mathrm{pH}$ measurements and $60 \mathrm{mM}$ methylamine for the ferricyanide reduction measurements.

\begin{tabular}{|c|c|c|}
\hline $\begin{array}{l}\text { Treatment of } \\
\text { Chloroplast } \\
\text { Lamellae }\end{array}$ & $\begin{array}{l}\text { Light- } \\
\text { Dependent } \\
\text { pH Change }\end{array}$ & $\begin{array}{l}\text { Rate of Photo- } \\
\text { reduction of } \\
\text { Ferricyanide }\end{array}$ \\
\hline $\begin{array}{l}\text { 1. None } \\
\text { None +uncoupler } \\
\text { 2. Low salt } \\
\text { 3. Low salt treatment } \\
\text { then readdition } \\
\text { of salt }\end{array}$ & 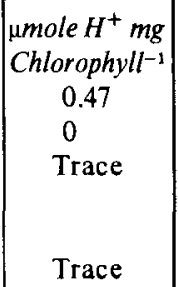 & $\begin{array}{c}\text { umoles } \min ^{-1} \mathrm{mg} \\
\text { Chlorophyll } \\
1.2 \\
9.6 \\
0.02\end{array}$ \\
\hline
\end{tabular}

\subsection{The Effect of Low Cation Concentrations up-} on Light-Dependent pH Changes

The increase in rate of photoreduction of ferricyanide after incubating chloroplasts in low salt concentrations is consistent with a time-dependent uncoupling of the chloroplasts. This has already been demonstrated by JAGENDORF and SMI'TH (23) and SPENCER and UNT (46). They found that removal of cations from chloroplasts by washing with $0.3 \mu \mathrm{M}$ EDTA and dilution in water resulted in loss of phosphorylative activity and this decrease in activity was prevented by monovalent and divalent cations, the divalent cation being about 100 times as effective as monovalent cations. Table VII shows that the capacity of chloroplasts to maintain a proton gradient in the light was also greatly reduced following exposure to a low concentration of salt. Unlike ferricyanide photoreduction, this capacity did not return with the re-addition of $\mathrm{NaCl}$.

\subsection{Effect of Low Concentrations of Cations on Morphology of Chloroplast Lamellar Systems}

If lamellar systems isolated in $30 \mathrm{mM} \mathrm{NaCl}$ were transferred to a low salt medium for 15 min (Table VIII), the residual grana disappeared and the vast majority of the thylakoids became swollen and deranged (Fig. 14). These membrane systems have been assigned to category 5 and correspond to chloroplast lamellae that have lost both photoreductive (Table III) and phosphorylative activity $(23,46)$ as well as the capacity to maintain a proton gradient in the light (Table VII). A few of the lamellar systems were resistant to derangement (Table VIII) and occasionally some containing grana (category 2) were encountered. These may have accounted for the small residual photoreductive activity of the preparations (Table III). In agreement with previous reports for spinach chloroplast membrane systems $(21,31)$ the addition of mono- or divalent cations to the deranged low salt lamellar systems of barley lead to a restacking of thylakoids (Fig. 15 to 20 ) referred to here as category 6 . These lamellar systems now showed a rate of photoreduction that was characteristic of uncoupled chloroplasts (Table III). As in the 
Effect of cations and methylamine on the morphology of lamellar systems.

Chloroplast lamellae were prepared as described in Materials and Methods, i.e. $30 \mathrm{mM} \mathrm{NaCl}$ was always present during the preparation. Where indicated in the table, $330 \mathrm{mM}$ sucrose was also present in all media. The lamellae were treated for $15 \mathrm{~min}$ in a low salt medium as described in Table III and where lamellae prepared in sucrosemedia were used $330 \mathrm{mM}$ sucrose was included during the low salt treatment. The preparations were illuminated for $2 \mathrm{~min}$ at $23^{\circ} \mathrm{C}$ with a tungsten lamp before fixation as described in Table I. Electron micrographs of the different categories of lamellar systems are given in Fig. 14 to 22.

i.th.sp. = intrathylakoid space.

\begin{tabular}{|c|c|c|c|c|c|c|c|c|c|}
\hline \multicolumn{3}{|c|}{ Treatment } & \multirow{3}{*}{$\begin{array}{l}\text { Number of } \\
\text { Lamellar } \\
\text { Systems } \\
\text { Analysed }\end{array}$} & \multicolumn{6}{|c|}{ Lamellar Systems Category, \% } \\
\hline \multirow{2}{*}{$\begin{array}{l}330 \mathrm{mM} \\
\text { Sucrose } \\
\text { Present } \\
\end{array}$} & \multirow{2}{*}{$\begin{array}{c}\begin{array}{c}\text { Resus- } \\
\text { pended } \\
\text { for } 15 \mathrm{~min}\end{array} \\
\end{array}$} & \multirow{2}{*}{$\begin{array}{l}\text { Thereafter } \\
\text { Salt Added }\end{array}$} & & With & \multicolumn{3}{|c|}{ Without Grana } & \multicolumn{2}{|c|}{ With Grana } \\
\hline & & & & $\begin{array}{c}2 \\
\text { i.th.sp. } \\
\text { wide }\end{array}$ & $\begin{array}{c}3 \\
\text { i.th.sp. } \\
\text { wide }\end{array}$ & $\begin{array}{c}4 \\
\text { i.th.sp. } \\
\text { dilated }\end{array}$ & \begin{tabular}{|c}
5 \\
de- \\
ranged \\
swollen
\end{tabular} & \begin{tabular}{|c|}
6 \\
re- \\
stacked \\
i.th.sp. \\
dilated
\end{tabular} & $\begin{array}{c}7 \\
\text { stroma } \\
\text { thyla- } \\
\text { koids } \\
\text { partially } \\
\text { collapsed }\end{array}$ \\
\hline $\begin{array}{l}- \\
- \\
- \\
- \\
+ \\
+\end{array}$ & $\begin{array}{l}- \\
+ \\
+ \\
+ \\
+ \\
+\end{array}$ & $\begin{array}{c}- \\
- \\
50 \mathrm{mM} \mathrm{NaCl} \\
0.5 \mathrm{mM} \mathrm{MgSO}_{4} \\
- \\
0.5 \mathrm{mM} \mathrm{MgSO}_{4}\end{array}$ & $\begin{array}{r}179 \\
20 \\
107 \\
61 \\
106 \\
43\end{array}$ & $\begin{array}{r}35.5 \\
\\
9.3 \\
13.1 \\
5.7 \\
23.3\end{array}$ & 5.6 & $\begin{array}{c}58.9 \\
5\end{array}$ & 95 & $\begin{array}{l}90.7 \\
86.9 \\
76.7\end{array}$ & \\
\hline- & - & $\begin{array}{l}60 \mathrm{mM} \text { methylamine } \\
60 \mathrm{mM} \text { methylamine }\end{array}$ & $\begin{array}{r}84 \\
180\end{array}$ & & & & & & $\begin{array}{l}100 \\
100\end{array}$ \\
\hline
\end{tabular}

case of the activity measurements, divalent cations such as $\mathrm{Mg}^{++}$were effective at lower concentrations than monovalent cations such as $\mathrm{Na}^{+}$(Table VIII). If $\mathrm{NaCl}$ (Fig. 15, 18 to 20) or $\mathrm{MgSO}_{4}$ (Fig. 16) were added, stacking of dilated and swollen thylakoids took place, but as illustrated especially in Figures 15 and 18, a reduction of intrathylakoid space generally did not occur. About 10 per cent of the lamellar systems had the appearance of category 2 and these were considered to be derived from the lamellar systems found resistant to unstacking and derangement upon low salt treatment. This category 2 (cf. left lamellar system in Fig. 17) increased to more than 20 per cent in a restacking treatment with $\mathrm{Mg}^{++}$following low salt treatment of lamellar systems in a medium containing $330 \mathrm{mM}$ sucrose and $30 \mathrm{mM} \mathrm{NaCl}$ (Table VIII). As mentioned above, the presence of sucrose specifically prevented expansion of the intrathylakoidal space and thus increased category 3 of the lamellar systems. These are presumably more resistant to swelling and derangement by low salt treatment and therefore permit reformation of category 2 of the lamellar systems upon addition of cations. The right lamellar system of Fig. 17, classified in category 6 , was considered to be derived from restacking of a category 4 lamellar system (cf. Fig. 3) This type was common in preparations made with media containing $330 \mathrm{mM}$ sucrose, a treatment that was assumed to make the lamellar systems more resistant to derangement by low salt treatment. As has been already described the addition of methylamine caused a restacking of thylakoids into grana and partial elimination of the intrathylakoid spaces in the stroma thylakoids (Table VIII, Fig. 21 to 24). This latter effect cannot be achieved by addition of cations at the concentrations used. 
The re-stacking of thylakoids into grana of standard diameter achieved with lamellar systems of completely separated thylakoids by either cations or methylamine suggests that the membranes of the thylakoid are differentiated into areas that can stack and areas where stacking cannot take place. Recent analyses of the composition of chloroplast membrane proteins in barley mutants deficient in either granal lamellae or stromal lamellae support this notion. Mutants that tend to pile all their thylakoids into grana are deficient in a hydrophobic protein of high molecular weight $(100,000)$, whereas mutant deficient in grana contain this membrane protein, but are deficient in one to three hydrophobic proteins with apparent molecular weights in the range 39,000 to 43,000 in a phenol-acetic acid-urea electrophoresis system $(37,43)$. These differences in the protein composition of the thylakoid membrane may reflect its differentiation into grana and stroma lamellar regions.

\section{DISCUSSION}

Three separate effects of cations on chloroplast lamellar structure and activity have been distinguished in this study. While other specific effects of cations may exist, many of the cationinduced changes in the morphology, structure, physical properties and activity of chloroplast membranes noted in the literature are explainable in terms of one or more of these three cation effects. The first effect is a requirement for relatively high cation concentrations to maintain stacking of the thylakoids in naked lamellar systems. Unstacking of the barley grana as a function of the cation concentration was not studied, but it is apparent from other studies that major reorganizations of lamellar membranes are reflected by changes in the light scattering properties of the membranes $(20,31$, 41). If the assumption is made that the onset of light scattering changes coincides with the start of thylakoid unstacking, then from the $90^{\circ}$ light scattering measurements of MURAKAMI and PACKER (31) it can be concluded that $200 \mathrm{mM}$ $\mathrm{K}^{+}$or 40 to $50 \mathrm{mM} \mathrm{Mg}^{++}$are minimum concentrations necessary to retain all of the grana in a tightly packed condition. Thus divalent cations are approximately 4 times as effective as monovalent cations. Very few of the media currently employed for isolation of chloroplasts contain such high concentrations of cations and even where such high concentrations are used in the isolation medium it is usual to transfer the chloroplasts into lower salt concentrations for assay of photochemical activity. Thus at least under assay conditions and often prior to this, a majority of the chloroplasts would contain mainly unstacked lamellae. This point appears to have been overlooked in many of the studies attempting to relate rates of photosystem II activity to the presence or absence of grana.

Measurements of light scattering also give an indication of the time course of the cationinduced structural changes related to thylakoid unstacking. The data of SHAviT and Avron (41) indicate that these changes take several minutes for completion at room temperature. In our experiments with a variety of media 10 to $30 \%$ of the lamellar systems (other than those prepared in $350 \mathrm{mM} \mathrm{NaCl}$ ) retained granal structures. Examination of the electron micrographs of categories 2 and 3 of the lamellar systems (Fig. 4, 5, 7 to 9) reveals a suggestive sequence of unstacking and swelling of the thylakoids. While these changes may continue for some time after isolation of the lamellar systems the relative amounts of lamellae with or without grana shown in Table I was altered little by storage of the preparations at $0^{\circ} \mathrm{C}$ for several hours. It seems that some chloroplasts are inherently more resistant to reduced cation concentrations (e. g. category 2 lamellar systems, Table I) than are others. This is perhaps not surprising as the barley leaf consists of cells of different types and physiological ages and whole leaf tissue is likely to release a heterogeneous population of chloroplasts.

The nature of the electrostatic and hydrophobic interactions which influence the stacking of lamellae and the role of cations in these interactions have been discussed by BERG et al. (7) and Murakami and Packer (31). The presence of grana is not necessary for Hill activity (Tables I and II) or proton pumping, although some related light-induced phenomena may be affected, e. g. enhancement (see below). 
The second and third effect of cations can be distinguished when the monovalent cation concentration in the medium is decreased to below about $10 \mathrm{mM}$. The change that such a decrease in the cation concentration causes again takes several minutes for completion at $23^{\circ} \mathrm{C}$, and is related to preservation of the integrity of thylakoid membranes. The second cation effect is a requirement of about $30 \mathrm{mM}$ monovalent cations for maximum activity of ferricyanide photoreduction, but this requirement is only seen after thylakoids have been exposed to a still lower cation concentration. The third effect of cations begins to become evident at monovalent cation concentrations below about $10 \mathrm{mM}$, and is the reguirement of cations for retention of a coupled activity for ferricyanide photoreduction. Both the ability to photoreduce ferricyanide (Table III, Fig. 29) and to support light dependent proton pumping (Table VII) are almost lost at monovalent cation concentrations $<2 \mathrm{mM}$, and other studies indicate that this is also true for photophosphorylation $(23,41,46)$. At the same time the thylakoid membranes become greatly extended and deranged (Fig. 14). These two cation requirements differ in concentrations, relative effectiveness of mono- to divalent cations (Table VI) and time courses.

It is to be noted that when chloroplasts are exposed to a large and rapid change in cation concentration, such as when chloroplasts or lamellar systems prepared in a high salt medium (e. g. $350 \mathrm{mM} \mathrm{NaCl}$ ) are rapidly diluted into distilled water, the thylakoids rapidly swell but a significant amount of appressed lamellar membranes remains $(22,25,31)$. In this case, loss of thylakoid membrane integrity may in some way stabilize the appression of adjacent membranes of damaged granal thylakoids.

The re-addition of cations to lamellar systems damaged and deranged by exposure to low cation concentrations results in stacking of thylakoids, but the extensive original granal stacks are not seen (ref. 31, Fig. 15, 16, 18 to 20) except in relatively few lamellar systems which seem more resistant to the low cation treatment. If the low salt treatment is less severe (i. e., shorter exposure times or higher cation concentrations) and causes unstacking but only limited thylakoid swelling $(7,21,31)$, extensive grana stacks can be reformed by addition of cations.

While the exposure of the chloroplast lamellar systems to low cation concentrations results in loss of activity for photoreduction of ferricyanide, photoreductive activity, but not photophosphorylation or proton pump activities, is regained by increasing the cation concentration (Table III). The new rate of ferricyanide photoreduction is about ten times the original rate and equal to the rate obtained with methylamine present in the reaction mixture. Thus exposing the lamellar systems first to low concentrations of cations and then replacing cations causes similar changes in activity as those produced by uncoupling photophosphorylation by methylamine. Presumably because of loss of thylakoid membrane integrity and ion leakage, generation of light-induced proton gradient is no longer possible, but photosynthetic electron transport reactions can take place provided cations are present in the medium. Methylamine causes stacking of membranes and collapsing of intrathylakoidal spaces, whereas replacement of cations only causes thylakoid stacking. Further experiments are needed in order to decide if these membrane associations play a role in obtaining uncoupled rates of ferricyanide photoreduction.

The multiple effects of cations on chloroplast photosynthetic electron transport activity appear to be explainable in terms of a leakage of cations from intra-and interthylakoid spaces. When the monovalent cation concentration in the external medium surrounding thylakoids falls below about $10 \mathrm{mM}$, the thylakoid membranes become permeable to cations which leak from intrathylakoid spaces. The addition of cations to the medium is then necessary to increase the cation concentration at the internal thylakoid surfaces to the levels required to support ferricyanide photoreduction. At another level of chloroplast organization the same explanation can be applied to the cation effect on lamellar stacking. Loss of the chloroplast outer envelope results in decreased cation concentration in the interthylakoid spaces and high concentrations of cations must 
be included in the medium to prevent the granal thylakoids from separating (cf. ref. 27). Chlorophyll fluorescence has been one of the most commonly used parameters for following cation induced effects on chloroplasts. The addition of cations to preparations exposed to a low salt treatment results in fluorescence changes $(12,15,16,19,30-35)$ which are probably closely related to the electron transport activity changes described in this paper involving cation effects 2 and 3 . The studies of Krause $(26,27)$ indicate that chlorophyll fluorescence changes also take place in the cation concentration range which affects thylakoid stacking (cation effect 1 ). The fluorescence yield was reduced and in particular, the long-term quenching of the fluorescence was lost after brief treatment of spinach chloroplasts in low ionic strength media. The time for this treatment, a few sec, was sufficient to remove the outer envelope from the chloroplasts, but probably was too brief to initiate any excessive swelling and loss of cations from the thylakoids. The original fluorescence signals were largely restored by addition of $5 \mathrm{mM}$ divalent cations or 150 to 200 $\mathrm{mM}$ monovalent cations (27).

The existence of fluorescence and delayed light emission changes (29) dependent on the same high cation concentrations necessary for stacking of the thylakoids suggests that at least some photosynthetic electron transport reactions are likewise dependent on the presence of similar concentrations of cations. The photoreduction of ferricyanide and the stimulation of this rate of photoreduction by methylamine takes place regardless of whether grana are initially present (e.g. in $350 \mathrm{mM} \mathrm{NaCl}$ ) or mostly absent (in 30 $\mathrm{mM} \mathrm{NaCl}$ ). However, at high cation concentrations (above $3 \mathrm{mM}$ divalent cations or $100 \mathrm{mM}$ monovalent cations) electron carriers located between photosystems I and II remain reduced during illumination with red light, whereas the same carriers are mostly oxidized in illuminated lamellar membranes suspended in low salt media (28). The same high concentrations of cations are necessary in order to demonstrate enhancement effects for NADP photoreduction $(28,42,48)$. These effects of high concentrations of cations have been in- terpreted as producing either a change in the distribution of pigments directing quanta to photosystem I and photosystem II (28), or a change in excitation transfer between the two photosystems $(9,32,48)$. While the appearance of cation-dependent enhancement in isolated lamellar systems is correlated with cation-dependent appression of thylakoid elements, it is not possible to conclude that the latter is necessary before enhancement can be demonstrated.

Our results then point out the importance that the concentration and valency of cations play in determining the configuration and conformation of isolated chloroplast membranes as well as the activity of membrane-bound electron transport systems. If the cation concentration in the medium is changed during any one of the steps of isolation, washing, storage or assay of the chloroplasts, this should be considered in the design and execution of experiments as well as in interpretation of results since there can be more than one effect of changing the cation concentration and at least two of these effects take several minutes for completion.

\section{ACKNOWLEDGEMENTS}

We gratefully acknowledge the skillful technical assistance of SUSANNE PLACING and Bibl ANDERSEN. This work was supported by grants from the Carlsberg Foundation, the USPHS National Institutes of Health (GM-10819 and GM-22051) and the Danish Natural Science Research Council.

\section{REFERENCES}

1. Anderson, J. M., D. J. Goodchild, \& N. K. Boardman. Composition of the photosystems and chloroplast structure in extreme shade plants. Biochim. Biophys. Acta 325: 573-585 (1973)

2. Anderson, J. M., K. C. WoO, \& N. K. BoArdman. Photochemical systems in mesophyll and bundle sheath chloroplasts of $\mathrm{C}_{4}$ plants. Biochim. Biophys. Acta 245: 398-408 (1971)

3. Appelqvist, L. A., P. K. Stumpr, \& D. von WETISTEIN. Lipid synthesis and ultrastructure of isolated barley chloroplasts. Plant Physiol. 43: 163-187(1968) 
4. Barber, J. \& G. P. B. KraAy. Salt-induced light emission from chloroplasts. Biochim. Biophys. Acta 197: 49-95 (1970)

5. BASZYNSK1, T., J. BRAND, R. BARR, D. W Krogimann, \& F. L. Crane. Some biochemical characteristics of chloroplasts from mineral deficient maize. Plant Physiol. 50: 410-411 (1972)

6. Benedict, C. R. \& R, J. Kohel. Photosynthetic rate of a virescent cotton mutant lacking chloroplast grana. Plant Physiol. 45: 519-521 (1970)

7. Berg, S., S. Dodge, D. W. KrogmanN, \& R. A Dilley. Chloroplast grana membrane carboxyl groups: Their involvement in membrane association. Plant Physiol. 53: 619-627 (1974)

8. Boardman, N. K., J. M. Anderson, A. Kahn, S. W. THORNE, \& T. E. TREFFRY. Formation of photosynthetic membranes during chloroplast development. In: Autonomy and Biogenesis of Mitochondria and Chloroplasts. N. K. Boardman, A. W. Linnane, and R. M. Smillie, eds. North Holland, Amsterdam, pp. 70-84 (1970)

9. Briantais, J. M., C. Vernotte, \& I. Moya. Intersystem excitation transfer in isolated chloroplasts. Biochim. Biophys. Acta 325: 530-538 (1973)

10. Bruinsma, J. A comment on the spectrophotometric determination of chlorophyl1. Biochim. Biophys. Acta 52: 576-578 (1961)

11. Gross, E. Uncoupling of photophosphorylation and inhibition of proton binding by quaternary ammonium salts and zwitterionic buffers, Arch. Biochem. Biophys. 147: 77-84 (1971)

12. Gross, E. L. \& S. C. Hess. Monovalent cation-induced inhibition of chlorophyll a fluorescence: Antagonism by divalent cations. Arch. Biochem. Biophys. 159: 832-836 (1973)

13. Gross, E. L. \& J. W. Libry. Cation induced inhibition of the $515-\mathrm{nm}$ absorption change in chloroplasts: Relation to structural changes. Arch. Biochem. Biophys. 153: 457-467 (1972)

14. Gross, E. L. \& L. PACKER. Ion transport and conformational changes in spinach chloroplast grana: I. Osmotic properties and divalent cationinduced volume changes. Arch. Biochem. Biophys. 121:779-789 (1967)

15. Gross, E. L. \& S. H. Prasher. Correlation between monovalent cation-induced decreases in chlorophyll $a$ fluorescence and chloroplast structural changes. Arch. Biochem. Biophys. 164: $460-468(1974)$

16. Gross, E., R. A. Dilley, \& A. San Petro. Control of electron flow in chloroplasts by cations. Arch. Biochem. Biophys. 134: 450-462 (1969)

17. Hall, J. D., R. Barr, A. H. Al-AbBas, \& F. L. CRANE. The ultrastructure of chloroplasts in mineral-deficient maize leaves. Plant Physiol. 50: 404-409 (1972)
18. Higlikin, H. R., N. K. Boardman, \& D. J. GoodChild. Photosynthetic studies on a pea-mutant deficient in chlorophyll. Plant Physiol. 44: 1310-1320 (1969)

19. Homann, P. H. Cation effects on the fluorescence of isolated chloroplasts. Plant Physiol. 44: $932-936$ (1969)

20. Izawa, S. \& N. E. Good. Effect of salts and electron transport on the conformation of isolated chloroplasts. I. Light-scattering and volume changes. Plant Physiol. 41: 533-543 (1966)

21. IZAWA, S. \& N. E. GoOd. Effect of salts and electron transport on the conformation of isolated chloroplasts. II. Electron microscopy. Plant Physiol . 41: 544-552 (1966)

22. Jacobi, G. \& E. Ptrner. Strukturelle und biochemische Probleme der Chloroplastenisolierung. Flora. 150: 209-226 (1961)

23. JAGENDORF, A. T. \& M. SMITH. Uncoupling phosphorylation in spinach chloroplasts by absence of cations. Plant Physiol. 37: 135-141 (1962)

24. JenNings, R. C. \& G. Fortı. The influence of magnesium on the chlorophyll fluorescence yield of isolated chloroplasts. Biochim. Biophys. Acta 347: 299-310 (1974)

25. KaHN, A. \& D. von WetTStEIN. Macromolecular physiology of plastids. II. Structure of isolated chloroplasts. J. Ultrastruct. Res. 5: 557-574 (1961)

26. KrausF, G. H. Light-induced movement of metal cations in chloroplasts, evidence from chlorophyll fluorescence and light scattering. In: Proc. 3rd Int. Congr. Photosynthesis, M. Avron, ed., Elsevier Scientific Publ. Co., Amsterdam, pp. 1021-1030 (1974)

27. Krause, G. H. Changes in chlorophyll fluorescence in relation to light-dependent cation transfer across thylakoid membranes. Biochim. Biophys. Acta 333: 301-313 (1974)

28. Marsho, T. V. \& B. KoK. Photosynthetic regulation by cations in spinach chloroplasts. Biochim. Biophys. Acta 333: 353-365 (1974)

29. Miles, C. D. \& A. T. Jagendorf. lonic and $\mathrm{pH}$ transitions triggering chloroplast postillumination luminescence. Arch. Biochem. Biophys. 129: $711-719(1969)$

30. Mohanty, P., B. S. Braun, \& Govindjee. Lightinduced slow changes in chlorophyll $a$ fluorescence in isolated chloroplasts: effects of magnesium and phenazine methosulfate. Biochim. Biophys. Acta 292: 459-476 (1973)

31. Murakami, S. \& L. Packer. The role of cations in the organization of chloroplast membranes. Arch. Biochem. Biophys. 146: 337-347 (1971)

32. Murata, N. Control of excitation transfer in photosynthesis. II. Magnesium ion-dependent distribution of excitation energy between two pigment systems in spinach chloroplasts. Biochim. Biophys. Acta 189: 171-181 (1969) 
33. Murata, N. Effects of monovalent cations on light energy distribution between two pigment systems of photosynthesis in isolated spinach chloroplasts. Biochim. Biophys. Acta 226: $422-$ 432 (1971)

34. Murata, N. Control of excitation transfer in photosynthesis. V. Correlation of membrane structure to regulation of excitation transfer between two pigment systems in isolated spinach chloroplasts. Biochim. Biophys. Acta 245: 365 372 (1971)

35. Murata, N., H. TAshiro, \& A. TAKamiya. Effects of divalent metal ions on chlorophyll $a$ fluorescence in isolated spinach chloroplasts. Biochim. Biophys. Acta 197: 250-256 (1970)

36. Newmann, J., J. Barber, \& P. Gregory. The relation between photophosphorylation and delayed light emission in chloroplasts. Plant Physiol. 51: 1069-1073 (1973)

37. Nielsen, N. C., K. W. Henningsen, \& R. M. SMillie. Chloroplast membrane proteins in wildtype and mutant barley. In: Proc. 3rd. Int. Congr. Photosynthesis. M. Avron, ed., Elsevier Scientific Publ. Co., Amsterdam, pp. 1603-1614 (1974)

38. Nishida, K. \& K. Koshil. On the volume changes of isolated spinach chloropiasts caused by electrolytes and sugars. Physiol. Plant 17:846-854 (1964)

39. OHKI, R., R. Kunieda, \& A. TAKamiYa. Effects of various cations on separation of the two photochemical systems by digitonin treatment. Biochim. Biohys. Acta 226: 144-153 (1971)

40. Robertson, D., \& W. Mc. Laetsch. Structure and function of developing barley plastids. Plant Physiol. 54: 148-159 (1974)

41. Shavit, N. \& M. Avron. The relation of electron transport and photophosphorylation to conformational changes in chioroplasts. Biochim. Biophys. Acta 131: 516-525 (1967)

42. Sinclair, J. Reversible abolition of enhancement in isolated spinach chloroplasts. Plant Physiol. 50: $778-783$ (1972)
43. Smillie, R. M., N. C. Nielsen, K. W. Henningsen \& D. von Wettstein. Ontogeny and environmental reguiation of photochemical activity in chloroplast membranes. In: Proc. 3rd. Int. Congr. Photosynthesis. M. Avron, ed., Elsevier Scientific Publ. Co., Amsterdam, pp. 1841-1860(1974)

44. Smillie, R. M., N. S. Scott, \& D. G. Bishop. Gene expression in chloroplasts and regulation of chloroplast differentiation. In: The Biochemistry of Gene Expression in Higher Organisms. J. W. Lee, and J. K. Pollak, eds., Australian and New Zealand Book Co., Sydney, pp. 479-503 (1973)

45. Spencer, D. \& J. V. Possingham. The effect of nutrient deficiencies on the Hill reaction of isolated chloroplasts from tomato. Aust. J. Biol. Sci. 13: 441-455 (1960)

46. Spencer, D. \& H. UNT. Biochemical and structural correlations in isolated spinach chloroplasts under isotonic and hypotonic conditions. Aust. J. Biol. Sci, 18: 197-210 (1965)

47. Spurr, A. R. A low-viscosity exposy resin embedding medium for electron microscopy. J. Ultrastruct. Res. 26: $31-43$ (1969)

48. Sun, A. S. K. \& K. SAuer. Pigment systems and electron transport in chloroplasts. Emerson enhancement in broken spinach chloroplasts. Biochim. Biophys. Acta. 256: 409-427 (1972)

49. Trebst, A. \& S. Reimer. Energy conservation in photoreductions by photosystem II. Reversal of dibromothymoquinone inhibition of Hill reactions by phenylenediamines. Z. Naturforsch. 28C: $710-716(1973)$

50. Vandermeulen, D. L., \& Govindjee. Relation of membrane structural changes to energy spillover in oat and spinach chloroplasts: Use of fluorescence probes and light scattering. Biochim. Biophys. Acta 368: 61-70 (1974)

51. WANG, A. Y. I. \& L. PACKER. Mobility of membrane particles in chloroplasts. Biochim. Biophys. Acta 305: 488-492 (1973) 